\title{
M1 Tank Driver Tests
}

Roy C. Campbell, Charlotte H. Campbell, C. Mazie Knerr Human Resources Research Organization

and

Susan L. Burroughs

Army Research Institute

ARI Field Unit at Fort Knox, Kentucky

Training Research Laboratory
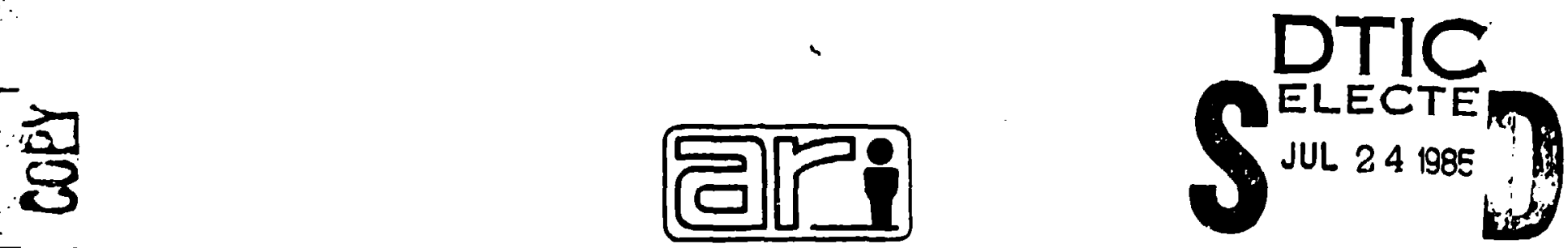

U. S. Army

D

Research Institute for the Behavioral and Soclal Sclences

February 1985

Approved lor public relesse: distribution unlimited. 


\title{
U. S. ARMY RESEARCH INSTITUTE \\ FOR THE BEHAVIORAL AND SOCIAL SCIENCES
}

\author{
A Field Operating Agency under the Jurisdiction of the \\ Deputy Chief of Staff for Personnel
}

EDGAR M. JOHNSON

Technical Director
L. NEALE COSBY

Colonel, IN

Commander

$r$

Research accomplished under contract

for the Department of the Army

Human Resources Research Organization

Technical review by

P.cb G. Witmer

Susan L. Burroughs

Theodore $\mathrm{R}$. Blasche

NOTICES
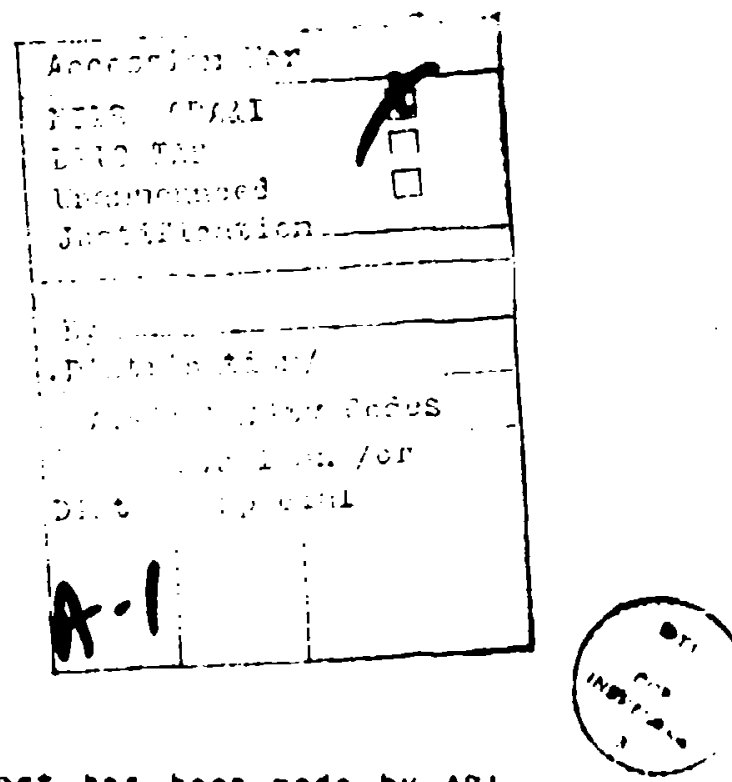

DISTRIBUTION: PrImary dIstribution of thls report has boen made by ARI. Plneso odjress correspondence concerning distribution of reports tos U.S. Army Reseorch instltute for the Benavioral ond Soclal Sclences, ATTN: PERI-TST, SOOI Elsenhower Avenue, Alexandrlo, VIrgInIo 22333.

FINAL DISPOSITION: InIs report moy be destroyed when it is no longer needod. Please do not roturn lt to the U.S. Army Research Institute for the Behovloral and Soclal Sclences.

NOTE: The IIndings In thls report are not to be construed as on oftlclol Deportmant of the Army dosltion, unless so designoted ty other outhorlzed documents. 


REPORT DOCUMENTATION PAGE
T. REPOAT NUMDEA
ARI Research Report 1391

MI TANK DRIVER TESTS

$\therefore$

$\because$

Roy C. Campbell, Charlotte H. Campbell, C. Mazle Knerr (HumRRO), and Susan L. Burroughs (ARI)

5. TYPE OF AEPSTT a PAIOD COVEAEO

Final Report

May 82 - Dec 82

READ INSTRUCTIONS
BEFORE COMPLETING FORM

9. PEAFORMINO OROANIZATION MAME AHO ADORESS

Human Resources Research Organization (HumRRO)

1100 South hashington Street

Alexandr1a, VA 22314

11. CONTROLLING OFFICE NAME ANO AOORESS

U.S. Army Research Institute for the Behavioral and Soctal Sciences

S001 Eisenhower Avenue, Alexandria, VA 22333-5600

6. PeRFonmino One. nePOAT NUMEé FR-TRD $(K Y)-82-8$

- CONTAACT ORORANT NUMGERTOS

MDA $903-80-C-0223$

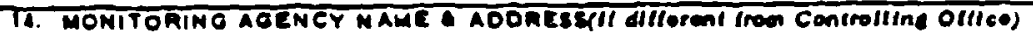

U.S. Army Research Institute for the Behavioral and Social Sciences

Fort Knox Field Untt

Fort Knox, Kentucky 40121

16. OISTAIQUTION STATEMENT (OI GIA Roport)

Approved for public release; distriburion unlimlted

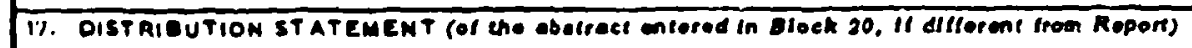

\section{SUPPLEMENTARY NOTES}

Technical quality of this research monitored by Donald M. Kristiansen.

19. KEY wOROR (Continue on reveroe elde II noceesen and ldonllly by block number)

M1 training

Ml driver simulator

Rellability measurement

Driver testing

Tank driving

Non-procedural tasks

20. AC TIACT (C)

, The purpose of this research was to develop reliable tests of nonprocedural Ml tank driver skilis that could serve as quantitative measures for tank-driver performance in simulators. Eleven driving tasks were derived from an Army Research Inst..tute criticality survey. Analysis of the tasks resulted in decisions to test nine of the tasks, but only those aspects that related to the driver and were feasible for testing. The tests were tried out on 77 soldiers in two MI OSUT classes. The data were used :0 assess scorer agreement and internal consistency, to estimate '(Continued) 
ARI Research Report 1391

\section{0. (Continued)}

validity and utility based on reliability and rariability and to direct revisions and recommendations for future testing. For each of the nine tests, the data indicated that driver performance could be measured reliably. Tests were designed so that usable quantitative data could be obtained. Although refinements and broader applications of the tests are required, the tests should serve the purpose for which they were designed. 


\title{
M1 Tank Driver Tests
}

Roy C. Campbell, Charlotte H. Campbell, C. Mazie Knerr Human Resources Research Organization and

Susan L. Burroughs Army Research Institute

\author{
Submitted by \\ Donald F. Haggard, Chief \\ ARI Field Unit at Fort Knox, Kentucky
}

\begin{abstract}
Approved as technically adequate and submitted for publication by Harold F. O'Nell. Jr.. Director Training Research Laboratory
\end{abstract}

U.S. ARMY RESEARCH INSTITUTE FOR THE BEHAVIORAL ANO SOCIAL SCIENCES

5001 Eisenhower Avenue. Alexendria, Virginis 22333

Orfice. Deputy Chief of Staff for Parsonnel

Deparrment of the Army

February 1985 
ARI Research Reports and Technical Reports are intended for sponsors of $R \& D$ tasks and for other research arid military agencies. Any findings ready for implementation at the time of publication are presented in the last part of the Brief. Upon completion of a major phase of the task, formal recom. mendations for official action normally are conveyed to appropriate military agencies by briefing or Disposition Form. 
The Automated Training Technology team of the Army Research Institute for the Behavioral and Social Sclences (ARI) performs research in areas that include the use of simulators and devices in military training. Of special interest is research in the area of evaluating simulators and devices in terms of transfer of training to the actual weapon system. In order to do this, however, specific objective tests of MOS skills must have been developed with criterion performance measures set.

This report provides rellable tests of non-procedural Ml tank driver skills that could serve as quantitative measures for tank driver simulator craining. The tests could also be of service to the Army for the determination of how well soldiers perform the different skills that are required during tank driver training and if skills are perfortoed to standard. The Aroy is currently organizing to train for NBC and extended operations maneuvers. The driving tests would be of value for the measurement of perceptual degradation affecting performance over time for the tank driver. The identified parameters which cause ferformance degradation can help structure training methods for the alleviation of the specific NBC and extended operations problems.

Further testing and evaluation of the developed Ml Tank Driver Tests will lead to the determination of criterion performance measures against which simulation tests can be compared. The criterion performance measures will yield a set base line for use in evaluation of tank design concepts for futuristic tank warfare by the U.S. Army Tank Automotive Command Tank Test Bed Program and Future Close Combat Vehicle Programs.

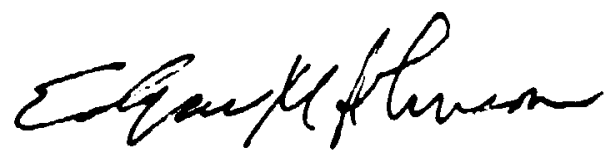

EDGAR M. JOHNSON

Technical Director 
This report deals with the testing of M tank drivers, focusing on the requirement to establish reliable measures of nonprocedural portions of the tank driver's job. The work was required under Task 21, Fleld Driving Test Situations for $M$ Drivers, which was perforwed for a project entitled, "Mission-Based Simulation and Training Requirements." Mr. Eugene H. Drucker is the project director.

The work was conducted by the Human Resources Research Organization (HumRRO) under Contract No. MDA 903-80-C-0223 with the U.S. Army Research Institute for the Behavioral and Social Sciences (ARI). It was performed at the Fort Knox, Kentucky office of HumRRO's Training Research Division, Mr. William C. Osborn, Director. Dr. Donald M. Kristiansen was the Contracting Officer's Representative.

A HumRRO staff member who contributed significantly to this work was Mr. Patrick Ford. Other HumRRo staff who worked on the profect were Bridgette $O^{\prime} B r i e n$, Eugene Drucker, Richard $O^{\prime} B r i e n$ and Richard Woods.

ARI personnel who assisted in the project were Merle Allen, Michael Anderson, and SP5 Leonard Cardwell. Major Robert Harold, ARI R\&D Coordinator, made arrangements for troop support.

CPT Kurt Bielefeld and CPT Ralph HHl, commanders of Company C and Company B, lst Battalion, 1st AIT/OSUT Brigade, Armor, and the non-commissioned officers of those units provided scorers, reviewers, equipment, administrative and troop support for the field tests. 
M TANK DRIVER TESTS

EXECUTIVE SUMMARY

Requirement :

Develop and assess the rellabllity of quantitative, on-5ank tests of nonprocedural, tactical M tank driving skills.

Procedure:

Eleven driving tasks for which tests were to be developed were derived from an ARI criticality survey. Analysis of the task resulted in decisions to test nine of the tasks, but only those aspects that related to the driver ani that were feasible for testing. Five of the tests were Obstacle/Judgment tests, and four were Tactical tests. The tests were tried out on 77 soldiers in two MI OSUT classes (none of the soldiers took all the tests). The data were used to assess scorer agreement and internal consistency, to estimate utility based on rellability and variability, and to direct revisions and recommendations for future testing.

\section{Findings:}

For each of the nine tests, the data indicated that driver performance could be measured rellably. Both the obstacle/Judgment tests and Itat Inal tests had been designed so that usable quantitative data could be obtained, and for every test, reflnements were suggested based on data and on informal observations. For two of the Tactical tests, an innovative scoring technique using an $M I$ tank proflle overlay was explored. Despite $h 1 g h$ ratings in the criticality survey, one Obstacle/Judgment test was recommended for deletion.

\section{Utilization of Findings:}

While more replications and developmental refinements of the tests are needed, the analysis and development performed have produced tests that are already minimally reliable. The tests were designed for use in measuring on-tank driving performance against which to assess driver simulator training. They may also be useful in general field applications for training. 
M TANK DRIVER TESTS

CONTENTS

Page

INIRODUCTION ........................... 1

objective ......................... 4

MEIHOD . . . . . . . . . . . . .......... 5

Tagk Select 1on ......................... s

Iritial Test Development . . . . . . . . . . . . . . . . . 6

Developmental Tryouts... . . . . . . . . . . . . . . 12

Test Revision......................... 14

Synopses of Obstacle/Judgment Tests ............... . 14

Synopses of Tactical Tests . . . . . . . . . . . . . . 13

Testing........................ 16

RESULTS ........................... 21

Results for the Tests...................... 21

Follow Ground Gulde Signals . . . . . . . . . . . . . . . 21

Right and Left Turns...................... 25

Al ign Tank for Width ................... 27

Width Judgment ....................... 31

Height Judgment ................... 33

Control Tank Iuring Main Gun Engagement . . . . . . . . . . . 37

Acceleration and Stopping .................. 38

React to TC Command - Missile, Duck . . . . . . . . . . . . 39

React to TC Command - Hull Defilade . . . . . . . . . . . 48

Test Intercorrelations ................. 56

DISCUSSION . . . . . . . . . . . . . . . . . . 65

RECOMMENDATIONS ....................... 69

BIBLIOGRAPHY . . . . . . . . . . . . . . . . . . 71

APPENDIX A - DRIVER PERFORMANCE TESTS . . . . . . . . . . . 73

\section{LIST OF TABLES}

Table 1. Driving Test Content ..................... 3

2. Number of Soldiers With Scorer Agreements on Barrier Strikes Before, Durlng and After the Turn and Overall for Follow

Ground Guide Signals Test... . . . . . . . . . . 23 
Page

3. Number of Barrier Strikes on Follow Ground Guide Signals Test. . . . . . . . . . . . . . . . . . . . 24

4. Time Statistics on Follow Ground Guide Signals Test . . . . . 24

5. Number of Soldiers With Scorers Agreements on Barrier Strikes Before, During and After the Turn and Overall for Right and Left Tums Test . . . . . . . . . . . . . . 26

6. Number of Barrier Strikes on Right and Left Turns Test . . . 28

7. Turn Radius and Time Statistics on Right and Left Tums Test........................ 28

8. Number of Soldiers With Scorer Agreements on Number of Strikes, Duration of Strikes, Portion of Tank, and Quarter of Passage for Align fank for Width Test .. . . . . . . . 29

9. Number of Soldiers With Correct Decisions by Gate and by Number of Correct Decisions for Width Judgment Test . . . . . 31

10. Number of Soldiers With cace Strikes by Gate and by Number of Gates Struck for W1dth Judgment Test . . . . . . 32

11. Number of Soldiers With Scorer Agreements By Gate and by Number of Correct Decisions for Height Judgment Test . . . . . 33

12. Number of Correct Decisions By Cate for Height Judgment Test. . . . . . . . . . . . . . . . . . . 34

13. Number of Soldiers by Number of Transmission Shifts on Control Tank During Main Gun Engagement Test . . . . . . . . . 37

14. Number of Soldiers By Acceleration Rating and Stopping Rating on Acceleration and Stopping Test.......... . 39

15. iumber of Soldiers By Rat Ings of Speed and Timing on Missile, Duck Test . . . . . . . . . . . . . . . . . . 40

16. Actual Test Times of Soldlers By Levels of Speed and Timing Ratings on Missile, Duck Test . . . . . . . . . . . . 41

17. Number of Soldiers With Scorer Agreements on Evaluation of Amount of Tank Exposure on Missile, Duck Test . . . . . . . 42

18. Number of Soldiers With Scorer Agreements on Pattems of Tapes Visible For Missile, Duck Test . . . . . . . . . . . 43

19. Number of Soldiers With Scorer Agreement on Tank Segments Exposed Using Profile Overlay Method For Missile, Duck Test . 44 
20. Number of Soldiers with Scorer Agreements on Three Patterns of Tank Segments Exposed Using Profile Overlay on Missile,

Duck Test...................... 46

21. Number of Soldiers in Three Categorles of Tank Exposure

Using Tape Method and Profile Overlay Method of Determining

Tank Exposure on Missile, Duck Test . . . . . . . . . . . 47

22. Number of Soldiers By Number of Tank Position Adjustments In

Each Direction and Overall on Hull Defllade Test . . . . . 49

23. Actual Test Times of Soldfers By Levels of Speed Rating on Hull

Defllade Test... . . . . . . . . . . . . . . . 50

24. Number of Soldiers With Scorer Agreements on Patterns of Tapes

Vistble on Hull Defilade Test............... 52

25. Number of Soldiers With Scorer Agreements on Tank Segments

Exposed Using Profile Overlay Method on Hu?.l Defilade Test - 53

26. Number of Soldiers With Scorer Agreements on Three Patterns of Tank Segments Exposed Using Proffle Overlay on Hull Defilade

Test .................... ss

27. Number of Soldiers With Scorer Agreements in Three Categories of Tank Exposure Using Tape Method and Profile Overlay Method of Determining Tank Exposure on Hull Defllade Test . . . . . 55

28. Driving Test Variables and Value Labels... . . . . . . 58

29. Intercorrelations (kendall) Among Variables on Follow Ground Guide Signals Test, Right and Left Turns Test, Allgn Tank For Width Test, and Width Judgment Test.............

30. Intercorrelations (Kendall) Among Variables on Helght Judgment Test, Conirol Tank During Main Gun Engagement Test, Acceleration and Stopping Test, and Missile, Duck and Hull Defilade Tests.... . . . . . . . . . . . .

LIST OF FIGURES

Figure 1. Tank segments for profile scorlng method .......... 45 
The potential requirement to fight outrumbered has created need for more effective training in today's Army. Rit high training costs, lack of sufficient training time, shortages of training areas, and high crew turnover rates have made the training manager's task very difficult. Several training innovations have been introduced and others are planned to help overcome the consequences of these problems. Among these are the development of new similators and training devices, and specialized training for opecific MOS related to particular weapon systems.

Among the simulators and crainers being developed is one for training drivers of the MI (Abrams) tank. The trainer is to cover nonprocedural cactical driving situations. Nonprocedural tasks are characterized by the fact that while the tasks remain constant, the conditions under which they are performed or the cues to which the soldier may respond are variable to a degree that it may be impossible to address all variations within a single analysis. To evaluate the craining effectiveness of the device, quantitative and objective measures for assessing actual tank driving performance on the Ml tank are needed to serve as criteria. The first steps toward development of the measures were to examine the existing driver tests and determine the criticality of nonprocedural Ml tank driving subtasks.

The present method for training tank crewmen during One Station Unit. Training (OSUT) requires that soldiers pass a series of performance tests before proceeding to the next phase of OSUT training. While the tests contain comprehengive coverage $c$ i tasks dealing with the preparation of the driver's, gunner's and loader's stations, they do not contain comprehensive tests of tank driving skills. Training site Certification (TSC) is generally used to assess driving skills. During TSC, soldiers are required to drive tanks in daylight over a designated course consisting of a paved track over level terrain. Measures consist of Pass/Fail checklist items related to basic driving skils (turns, acceleration and stopping, smoke generator operation). The course must be completed within 30 minutes. 1

\footnotetext{
IThis TSC course descripton is as of May 1982. Ml OSUT dri:ing is an area of emphasis and the TSC is subject to change in content and duration with subsequent OSUT classes.
} 
Classtoom instruction in OSUT presents information on tactical driving (e.g., selection of routes and positions) but TSC offers the only actual driving opportunity for the trainees. Unless resources (e.8., fuel and tanks) increase substantially, this limitation on daiving is likely to continue. While TSC involves verification by a trainet that a soldier has received driver training and has, in fact, driven a tank, it contains no provisions for testing how well soldiers can perform the different skills that are required during tank driving, nor does it result in a quanticative measure that can be used to determine whether or not the akills can be performed to standard.

Tank driving skills are developed in the unit and, correspondingly, tests are developed for assessing driving in the unit which cover skills more advanced than the OSUT test. Driving mastery and readiness tests have been developed for the M48 (Baker and Roach, 1960) and M60Al Canks (O'Brien, Harris, Osborn, and Healy, 1979; Eaton, Bessemer, and Kristiansen, 1979). Like the OSUT tests, chese readiness tests require subjective ratings (Pass/Fail scores on checklists) of the driver's ability to perform a series of steps or characteristics of the driving tasks.

Table 1 summarizes the driving activities in the tests. In general, the OSUT cest contains more of the basic skills and the tests by O'Brien et al. and Eaton et al. contain more of the advanced, tactical skills such as driving during engagements.

The research by Eaton et al. reports the development of the driving tests and theit use as criterion measures. Eaton et al. examined the use of aptitude tests, other pencil and paper measures, and OSUT measures to predict driving skills. Since no generally accepted measures existed for tactical driving skills, they developed a driving course and performance measures. As a starting point, they used a driving course checklist from Greenstein and Hughes (1976) and augmented it with driving tasks selected by panels of NCO driving instructors. The final "Advanced Driving Checklist," designed for tank commanders (TC) to gcore drivers, contained the driving skills shown in Table 1 . 


\begin{tabular}{|c|c|c|c|c|c|}
\hline Driving Activities & $\begin{array}{l}\text { OSUT } \\
\text { TSC } \\
\end{array}$ & $\begin{array}{l}\text { Baker } \\
\text { Roach } \\
\end{array}$ & $\begin{array}{c}\text { Driving Te } \\
\begin{array}{c}\text { do'Brien } \\
\text { et al. }\end{array}\end{array}$ & $\frac{\text { Eaton }}{\text { Basic }}$ & et al. \\
\hline $\begin{array}{l}\text { Drive the Tank } \\
\text { Accelerate/maintain opeed } \\
\text { Turns } \\
\text { Stop } \\
\text { Back atraight } \\
\text { Varied/natural terrain }\end{array}$ & $\begin{array}{l}x \\
x \\
x \\
x\end{array}$ & $\begin{array}{l}x \\
x \\
x\end{array}$ & 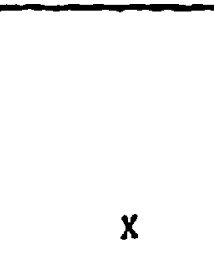 & $\begin{array}{l}\mathbf{x} \\
\mathbf{x} \\
\mathbf{x}\end{array}$ & \\
\hline Operate swoke generator & $\mathbf{x}$ & & & & \\
\hline $\begin{array}{l}\text { Drive over an obstacle } \\
\text { Drive across a ditch }\end{array}$ & $x^{a}$ & $\begin{array}{l}x \\
x\end{array}$ & $\begin{array}{l}x \\
x\end{array}$ & & \\
\hline Drive up/down ateep hill & $x^{a}$ & $\mathbf{x}$ & $x$ & & $x$ \\
\hline $\begin{array}{l}\text { Follow hand/arm signals } \\
\text { Perform evasive maneuvers upon enemy contact } \\
\text { Drive into defilade firing position } \\
\text { upon enemy contact }\end{array}$ & & $x$ & $x$ & $\mathrm{x}$ & \\
\hline $\begin{array}{l}\text { Drive in response to fire command } \\
\text { Coax area target } \\
\text {.50 cal. area target } \\
\text { Halt for coax point target } \\
\text { Halt for .50 cal. point target } \\
\text { Halt for main gun target } \\
\text { Flank moving coax engagement } \\
\text { Main gun engagement-hull defilade } \\
\text { Main gun engagement-from road } \\
\text { Main gun engagement }\end{array}$ & & & $\begin{array}{l}x \\
x \\
x \\
x \\
x\end{array}$ & & $\begin{array}{l}\mathbf{x} \\
\mathbf{x} \\
\mathbf{x} \\
\mathrm{X} \\
\mathrm{X}\end{array}$ \\
\hline Acquire targets & & & $x$ & & \\
\hline Observe/sense rounds & & & $\mathrm{x}$ & & \\
\hline Starting/stopping procedures & & & & $x$ & \\
\hline Operate amplifier audio frequency & & & & $x$ & \\
\hline Operate intercom control & & & & $x$ & \\
\hline Radio check & & & & $x$ & \\
\hline Ground guide--give hand/arm signals & & & & $x$ & \\
\hline Drive buttoned up & & & & $x$ & \\
\hline Drive on paved road & & & & $x$ & \\
\hline
\end{tabular}

a In May 1982 :he TSC driving location did not fully support evaluation of these activities. 
In their next research phase, Eaton et al. more strongly emphasized tactical driving. They developed measures in which the TC rated the trainees' overall driving skills on a seven-point scale and completed a checklist. The checklist items set forth the TC role and potential driver responses (e.g., "Main gun engagement. When TC instructs driver to find defilade position and issues fire comand does driver. ."). The tactical situations were: main gun engagement, moving coax engagement, ditch crossing, main gui, engagement from hull defilade position, main gun engagement frow road, and flank woving coax engagement.

Eaton et al. noted the problems of rater reliability in the use of observational ratings and checklists, but their deaign did not permit direct assessment of reliability. The current. research extends the development of tactical driving criterion measures to the assessment of reliabiity.

Objective

The overall goal of the research is to design measures of driving skills, using quantitative scoring techniques which can be implemented by Army personnel. The quantitative measures will focus on the underlying continuous perceptual motor skills, perceptual judgments, and dacisionmaking critical to performance of driving tasks. Specifically, the objective is to develop and assess the reliability of quantitative, on-cank tests of nonprocedural, tactical Ml tank driving skills. The purpose of the effort is to develop criteria against which driver oimulator performance can be compared. 
METHOD

Task Selection

Initial selection of tactical skills was based on a criticality assessment questionnaire developed and administered by the Army Research Institute (Burroughs, 1981).

Driving subtasks were 1 isted in questionnaire which asked Ml drivers to race the subtasks on three dimensions of criticality: driving practice time needed to become skillful, importance to accomplishing assigned combat missions, and consequences of inadequate performance. The criticality dimensions were chosen from the Training Development Handbook Phase I: Analysis, a description of instructional systems development procedure, for use by the U.S. Army Armor Center, (April 1978). These procedures are based on the Interservice Procedures for Instructional systems Development described in the five-volume TRADOC Pamphlet 350-30. Although the major concern of the Research was to determine which driving skills were critical to accomplishing assigned combat misoions, it seemed logical to view this dimension in relation to both learning difficulty and consequences of inadequate performance. Consequences of inadequate performance are those which result in injury to personnel, loss of life, or darage to the tank. The three dimensions taken together estimate the importsnce of simulating these skills on a training device. If, for example, the skill is critical to accomplishing assigned combat missions, but is learned rapidly and has negligible consequences if performed inadequately, it might not be costeffective to aimulate conditions for practice of the skill on a low-cost device. The low-cost device is best used and most cost-effective for critical skills that are difficult to learn (require wuch repetition) and have extremely serious consequences if performed inedequately.

The most valid evaluation of which tank driving subtasks are critical is made by non-comissioned officers with $M 1$ tank driving experience. Twenty-five non-commissioned officers, $2 / 6$ Cavalry and $1 / 1$ AIT OSUT Brigade, including $M I$ tank instructors at Fort Knox and thirty-five noncomissioned officers, 2/67 Armor, with unit driving experience from Fort hood, rated the aubtasks for the evaluation. After filling out the 
questionnaire, each NCO was interviewed to determine both adequate and insufficient training he had received on the various Ml driving skills. The soldiers were also quaried as to the level of decision-making a driver is expected to execute during combat situations, and what level of decision-making he was trained to do and does in unit driving.

Based on those results, 11 tasks were identified as candidate tasks for testing:

- Pass Under Overhead Obstacle
- Negotiate Narrow Passage
- Maintain Steady Firing Platform
- Minimize Exposure Time in Open Terrain
- Turn Glacis Toward Greatest Threat
- Drive Up/Down Inclines (Under 31 Degrees)
- Drive On Side Slopes (Under 22 Degrees)
- Perform Missile Evasive Maneuvers
- Load Tank on Rail Car
- Respond To TC Maneuver Directions
- Perform Pop-Up Firing Technique

This task listing was to provide the nucleus of critical skilly around which testing would focus. The emphasis in the test development was to be on quantitative cricerion measures and reliability. There were four main phases to accomplish this goal:

- Initial Test Development

- Developmental Tryouts

- Test Revision

- Testing

Initial Test Development

Initial test development involved two steps:

1. Analysis of tasks selected

2. Development of scoring instruments 
Step 1. Analysis of Tasks Selected. The position of the tank driver is probably the poorest defined of all the crew positions. Procedurally, the actions of the driver are simple--starting, otopping, accelerating, braking, etc.--but operationally his skills become complex and are not well documented. The driver of a tank does not occupy a role that is operationally separate from the rest of the crew. Interaction with other crewmembers, particularly the tank commander, is constant and ultimately the tank commander is responsible for the speed, direction and movement of the vehicle. The situation is confused by the fact that there are many variations in driver responsibilities from crew to crew and the experience of the driver and the expectations of the tank commander dictate how much independent driver action is allowed or expected. A further complication is that the driving requirements of most tactical tasks are extremely situational and, while driving procedures can be identified, the sequence, interactions and execution of those procedures are difficult if not impossible to delineate except in the context of a specific situation.

The tasks selected from the ARI questionnaire did not include any de.* tailed description defining the scope of the activity involved. Therefore a separate analysis step was required before test development.

The 11 tagks originally selected were divided into two groups, i.e.:

Tactical

Minimize Exposure Time in Open Terrain

Perform Missile Evas ive Maneuvers

Maintain Steady Firing Platform

Perform Pop-Up Firing Technique

Turn Glacis Toward Greatest Threat

$\because \quad$ Respond To TC Mareuver Directions

Obstacles

Luad Tank on Rail Car

Negotiate Narrow Passage

Pass Under Overhead Obstacles

Drive on Side Slopes (Under 22

Degrees)

Drive Up/Down Inclines (Under 31

Degrees) 
An informal analysis of each task was performed using available literature and knowledge of the task. The analysis was conducted with a view toward testing primarily with conventional measurement means; i.e., observation.

The analysis of the tactical tasks confirmed the ambiguity of the driver's role and the team-task nature of the performances. To wore accurately define the driver's role in many of the listed tasks it was determined that a much more detailed analysis of the crew performance would be required using team-task analysig. Additionally, the preliminary analysis identified a variety of performances possible under the identified Tactical tasks. For example:

- Perform Missile Evasive Maneuvers. Three types of performances are possible--Duck, DoĊge or 2 ig Zag--depending on the circumstances of the missile engagement. Further, the three performances can occur separately or in conjunction with each other. While $\mathrm{Zig} \mathrm{Zag}$ is the most common it is also the most demanding in terms of vehicle risk and terrain requirements.

- Perform Pop-Up Firing Technique. The nature of the task changes, depending on whether the rask is performed in conjunction with a deliberately prepared defensive position, a hasty defensive position, or as an offensive firing technique. Further, the task is most often performed in conjunction with other tanks in the section. In some situations the primary responsibility and skill lie with the gunner, not the driver. Tactically it is often a preplanned or rehearaed activity.

- Respond To TC Maneuver Directions. As a task this is totally dependent on the situational conditions, In fact, it is probably not a separate $t a s k$ but is an inherent part of most tactical tasks.

- Turn Glacis Toward Greatest Threat. This is dependent on terrain, threat and other ongoing requiled tank activity. It is generally performed as part of maneuver, not firing, and is a technique incorporated in other tasks rather than a separate task. Implied in the cask statement ("greatest threat") is a driver judgment of multiple threat capability--a difficult and complex requirement.

- Minimize Exposure rime in Open Terrain. This activity is dependelt on terrain, threat, tank missions and surrounding activity to include section/platoon actions and 
support available. The responsibility for route selection, route correction and selection of positions lies primarily with the tank comander. In many situations, and particularly for novice drivers, the driver's responsibility is in execution, not selection.

Maintain Steady Firing Platform. As driver task, this is highly dependent on the craining and expectations of the crew. Emphasis is on eliminating or minimizing anything that would interfere with the gunner actions but this is highly dependent on the terrain and other tactical conditions, including the type of fire being delivered (assault, suppressive, precision). Requirements are most often expressed in ambiguous terms such as "smooth," "steady," "even," and "avoid unnecessary obstacles," which are given without standards or further usable definition. The skill of the gunner, duration of the engagement, expected outcome of the engagement and support available all affect the driver requirements and it is difficult to isolate the specific driver responsibilities, much less define them for observer measurement for test purposes.

The analysis of the Obstacle tasks revealed that the tasks were not as definitive as they first appeared:

- Load Tank on Rail Car. Essentially a ground guide task; in fact, the positioning and control of the tank are entirely the ground guide's responsibility. The driver must merely follow the ground guide signals. The poychological implications of knowing that he (the driver) can fall off the platform and the movement of the platform itself are the biggest factors that affect the driver. In testing, these are difficult to simulate. (It was assumed that actual flat cars would be unavailable for testing.)

- Negotiate Narrow Passage and Pass Under Overhead Obstacles. These tasks are rarely performed unassisted and in the case of Negotiate Narrow Pasage is, in extremely close situations, performed with ground guide, removing any responsibility or judgment from the driver. Ulcimately decisions on passing these obstacles lie with the tank commander. This is especially true of passing overhead obstacles where the TC (or loader) is in a better physical location to judge clearance. Passage under overhead obstacles is also dependent on conditions. "Soft" obstacles such as tree limbs can be negotiated with less risk than hard obstacles such as overpasses. Height requirements also vary with the nature of the obstacle. An overpass that will strike the antenna presents no risk but an electrical line within antenna height presents a high risk situation. 
- Drive on Side Slopes of 22 Degrees and Drive Up/Down Inclines of 31 Degrees. The 22 degree lofe and 31 degree incline capabilities of the Ml tank are theoretical capabilities. Under field conditions the climbing capability of the $M I$ is dependent on the propensity to shear soil off the rear and sides of the track. This propensity is a factor of both the vehicle and the cype (sandy, clay, gravel) and condition (wet, moist, dry) of the soil. To determine the potential ability of the MI to navigate any given uniform slope it is necessary to determine the MI Vehicle Cone Index (VCI) and the soil Rating Cone Index (RCI). RCI is determined by performing soils test under the exfected navigation conditions (wet, moist, dry). Applying the RCI and VCI to performance curves can then deterwine the maximum ascendable slope. This would change somewhat during testing, however, if the same "track" were repeatedly used. It was assumed that for testing purposes it would be necessary to find a slope or series of slopes that would denand the maximum capability of the vehicle in order to judge driver skill by his ability to navigate it successfully. In other words, the slope should be passable but not "easily" navigated. The preparation for such a test, while not impossible to accomplish, is nonetheless considerable. More importantly, there were no accessible inclines in the proposed cest site area that approached the slope requirements.

Following the preliminary analysis, a meeting was held with the ARI task leader and project staff to discuss the findings of the analysis and decide on a preliminary approach to testing. As a result of this meeting it was decided:

- To forego tean task analysis which might isolate driver requirements and allow driver testing in a crew context. The time required and uncertain results of team task analysis precluded this approach.

- To change the nature of the "task," where necessary, to test only those aspects that related to the driver and were feasible for teating. An important part of this decision was to name precisely what was being tested, which in most cases was not the sare as the task listed. For example, Acceleration and Stopping could be tested instead of the task, "Perform Pop-lip Firing Technique." Acceleration and Stopping is contributory to pop-Up Firing Technique but it is not the entire task nor, perhaps, even the most important part of the task. In some cases what resulted were not even tasks but rather behaviors or judgments related to tasks. An important point was in renaming the tests to avoid creating the impression that whole task performance was being evaluated where it was not. 
- Not to be overly constrained by reality in deciding the behaviors to be rested; or, more preciaely, to construct the test around situations that did not necessarily reflect realistic job situations. For example, the task, "Negotiate Overhead Obstacles," is realistically not performed without TC/loader interaction and assistance. By changing the task to a test of "Judging Overhead Clearance," the driver can be forced to make the decision on his own without contaminating what he has learned to do and what he is supposed to do in the actual job aituation.

- To drop unfeasible tasks. Tasks such as those involving the 22 degree 8 lope and 31 degree incline and the Exposure Time in Open Terrain are difficult to standardize in a test situation. Given the terrain available at Fort knox for testing, they were completely impractical because of lack of requisite slopes and space and terrain requirements. Rather than change the test location, the tasks were dropped.

The result was a reordering and, in most cases, renaming of the tests. The tested behaviors were no longer referred to as "tasks" to avoid confusion with the existing full crew behaviors that are more rightly called tasks. The resulting tests were:

\section{Tactical}

React To TC Command (Hull Defilade) React To TC Command (Missile, Duck) Drive Tank During Main Gun Engagement Acceleration and Stopping

\section{Obstacle/Judgment}

Judge overhead Clearance

Judge Width clearance

Follow Ground Guide Signals

Step 2. Development of Scoring Instruments. Preliminary test development concentrated on producing scoresheets that focused on two areas; i.e.:

$$
\begin{aligned}
& \text { Off-vehicle scoring } \\
& \text { - Quantitative measurement }
\end{aligned}
$$

off-vehicle scoring was desirable in order to facilitat a determination of intertater reliability and to reduce reliance on the IC or other crewmember who is often distracted or preoccupied with his own role requirements during testing. Quantitative measurement was needed in order to establish a range of performance and to avoid dichotomous classification of 
performance measures. The wide range of possible behavior and the eventual need to establish how much of this behavior could be captured in simulator performance were also determinants of the requirement for quantitative measurement.

Not all tests could be fully scored by such methods. Time measures were included in all instruments but this was the only universal quantitative measure. Some tasks (e.g., Judge Overhead clearance) did not lend themselves to a single quantitative performance evaluation--the judgment was either correct or it was not. However, a series of judgrent requirements could be introduced.

Some measure of performance from a remote or off-vehicle location was obtainable on all tests except one (Drive Tank During Main Gun Engagement). However, in the tactical category of tests it was determined that not only was scoring by the $\mathrm{TC} /$ gunner necessary, it was also desirable. In these tasks, instead of trying to avoid subjective TC evaluation (e.8., smooth stop, steady acceleration), it was decided to concentrate on some aspects of subjective evaluation, correlating such evaluations with the objective, quantitative measures simultaneously obtained, resulting in a better definition of the subjective cerms for future use.

In additioll to the scoring instruments (scoresheets), instructions for setting up and administering the test were also prepared.

\section{Developmental Tryouts}

A one-day pilot performance of all the prepared tests was conducted at Fort Knox at the area known as Pickett Driving Range and in the adjacent area to the south of the driving oval generally used for vehicle recovery training. This area was also to be used for actual testing; however, it was not entirely suitable for the tests to be conducted. Space was limited and terrain was marginally adequate for most of the tactical tests and inadequate for others; therefore, three tests had to be dropped. However, it contained some needed hardstand and it was immediately adjacent to the driving range from which test subjects would be obtained--a prime consideration for the choice of location. 
The 1st AIT OSUT Brigade, Armor, provided the equipment (one Ml tank) and personnel for the tryout. Personnel consisted of seven NCO (E-5 and E-6) who were MI OSUT trainers. Thus they served as oubject matter experts for technical review of the material as well as specialists in OSUT training, in addition to serving as performers, TC and scorers. There were no subjects per se tested.

The main conclusions from the developmental pilot test were:

- The MI is operationally much more technically sophisticated in movement than anticipated. Firing on the move, for example, requires much less driver attention to bumps, terrain interruptions, and turns than did the M60 series. Except for shifting, there is very little skill required from the driver in maintaining a steady platform when operating at moderate speeds in even moderately rough terrain.

- OSUT trainees (the target test audience) are vircually cotally unfamiliar with any tactical employment of the vehicle. Terminology such as hull defilade and missile evasion would mean nothing to them and they would have to be trained in what is expected of them prior to any testing. The same is true of controlling the tank during main gun engagement.

- When actually tested, OSUT trainees would have had approximately 15 minutes of driving experience. Mistakes would be numerous; some mistakes could be potentially dangerous. OSUT trainees would probably rely heavily on instructions from the TC; they would not perform many steps without the TC "OK," even after being instructed on what to $\mathrm{ds}$. This could be a problem in testing in that it introduces the aspect of cued behavior with some examinees. Test instruments are not designed to accommodate this.

- Width judgment has more facets than originally anticipated and includes such considerations as deciding whecher clearance is possible and navigating the obstacles once the decision is made. Because of the frequent requirements for skills relating to width maneuver, this area was judged highly important. Height judgment on the other hand appears to have limited application, is "easy" to judge, and requires no skill once judgment is made. Of all the tests piloted, height judgment was thought by SME to have the least application. 
- All piloted tests were determined to be feasible. Major modifications were suggested in the main gun engagement test and on width judgment, but most of the remaining tescs required only minor rodifications and clarifications.

Test Revision

Based on the developmental tryouts, two tests were added and other - rested modifications were made to the other tests. Equipment requirements and scoring instructions were also finalized. The revised tests are contained in Appendix A. A brief synopsis of each test is contained below. The diatinction between Tactical tests and obstacle/Judgment rests was retained as a convenient administrative classification. In actuality the distinction has no implication for level or difficulty of skills nor for applicability to whole task performance. The Tactical tests, for example, involve measures of discernable individual skills and should not be construed as directly predicting actual full tactical performance. Neither category of task should be judged as more important or meaningful than the other.

\section{Synopses of Obstacle/Judgment Tests}

- Follow Ground Guide Signals. Designed to measure the driver's skill in responding to ground guide signals in a tight maneuver situation. Because a ground guide is used, the control of the tank is essentially the sround guide's responsibility. Any barrier strikes were assumed to be the result of the failure of the driver to respond correctly to the ground guide signals. Time measures reflected the need for adjustments in movement. All tank movement was while driving in reverse, with steering opposite that of forward movement.

- Right and Left Turns. Designed to measure the driver's skill in maneuvering in a constricted area without assistance. The driver's instructions were to stay as close as possible to an engineer tape barrier without striking it. Two 90 degree turns, one left and one right, were included. The barrier existed on only one side of the tank; the other side was open.

- Align Tank for Width. Designei to measure L Jriver's ability to control and adjust the position of the tank within narrow confines without assistance. Drivers negotiated a straight passage with engineer tape barriers on each side. The pasage entrance was 205 inches and each side narrowel to a 157 inch exit. The 
barrier was set at fender height. The drivers made a 90 degree or greater turn into the passage about 10 meters from the passage entrance.

- Width Judgment. This test consisted of three sets of movable gates, one set of which was too narrow for the tank to pass through ( 144 inches). The other gates were set at 157 inches and 169 inches. If the driver judged that he could clear the set of gates, he was to drive through the gates; if he judged he did not have clearance, he was to bypasa. The location of the narrow gate was changed after each examinee. Skills measured included accuracy of each width judgment, steering and positioning of the tank, control of the tank and a time measure reflecting both the decision and control.

- Height Judgment. Designed to measure the driver's perception of overhead clearance and his judgment of close tolerances, and to identify points of confusion in height judgment. This test consisted of six gates with overhead barriers set at heights of $114,115,116,117$, 118 , and 119 inches clearance. All but the 114 inch barrier are passable by an Ml tank with the TC hatch in the protected position. Drivers were to pass under those gates they judged passable and to bypass any gate they jidged unpasable. The location of the 114 inch gate was to be moved for each examinee. All judgments were made without assistance.

\section{Synopses of Tactical Tests}

- Control Tank During Main Gun Fingagement. Designed to measure the driver skil at minimiz:ng anything that interferes with the gunner while engaging cargets on the move. It was also to identify driver behavior in orienting the front of the tank toward the target and in reacting to impassable obstacles in the path of the tank during the engagement. Primary measures were to be the gunner's evaluation of the percent of time he was able to maintain lay on the target and a count of the number of transmission shifts during the engagement. Time to traverse the standardized engagement distance reflected the driver's ability to maintain a constant speed. Subjective TC evaluations were gathered for experimental use.

- Acceleration and Stopping. The driver, on command and from a stop, accelerated as fast as possible and stopped as close as he could to a marked line within right and left boundaries. Measures included the driver's skills in judging tank stopping distance and his ability to control the tank in rapid acceleration/rapid decelera$t$ ion conditions. 
React to TC Command - M18sile, Duck. Upon command, the driver was expected to move to a position of total defllade. Sk1lls measured were the driver's reaction time, vehicle control, vehicle position and the driver's judgment of the vehicle size and shape relative to other objects (the defilade). To some extent the test measured the driver's understanding of the missile evasion concept. Subjective TC evaluations were gathered for experimental use.

React to TC Command - Hull Defilade: Upon command, the driver was to move to a position of hull defilade with the gun capable of engaging the target (free of obstructions). Skills measured were the driver's reaction time, vehicle control, vehicle position control, vehicle position and the ablitty tc obtaln hull defilade. To some extent the test was to measure the driver's understanding of the hull defilade concept. Subjective TC evaluations we re gathered for experimental use.

Testing

Testing Schedule. Testing was conducted in two phases. During May 1982, all the Obstacle/Judgment tests except one were cesced over a two-day period. Helght Judgment was not tested at this t1me because of equipment problems. All Tactical tests plus the Helght Judgment tests were administered on one day in September 1982. All testing was conducted at Fort Knox, Kentucky. The May testing was conducted at the Plckett Driving Range area which was also used for the developmental tryouts. The September testing was conducted at Training Area 13, which afforded more room and more variation in terrain.

Test Subjects. In May, $44 \mathrm{MI}$ OSUT trainees were tested; In September 33 different $M 1$ OSUT trainees were tested. Both groups' previous hands-on driver training consisted of approximately 15 minutes of driving on the TSC course.

OSUT personnel were tested because of the1r avallability and the un 1formity of their pretest experience. However, the tests were not designed as a measure of OSUT sk111s. None of the tests had been spectfically trained in OSUT with the possible exception of Ground Guide Signals. Some of the tactical skills were covered in instruction but not practlced. The refore, soldiers were told the requirements of the Missile, Duck and 
Hull Defilade exercises at least twice immediately before teating. The inconsistency of the test content with the experience and performance level of the examinees could have influenced the testing outcome since more performance cues were required to compensate for their lack of experience.

Scorers. Eleven military and seven civilian scorers administered the tests. Each tank had a military TC and ailitary person as a ground guide. All military personnel were NCO in the rank of $E-5, E-6$, or $E-7$, assigned to che $1^{\text {st }}$ AIT/OSUT Brigade, Arwor. Civilian scurers were HumRro personnel. When feasible two scorers obtained the same measure and, where resources permitted, military ard civilian scorer were paired to obtain the measure.

Scorers received a briefing on their requirements and, where posaible, a walk-through of the tests. However, because of equipment and personnel availability the scorers lacked the full training regimen of a field test for test validation. This requirement should be emphasized in sny test replication.

Test Organization. The first phase of testing (Obstacle/Judgment) was organized into two stations. The first station tested Ground Guide signals and Left/Right Turn. Both tests were conducted on the same phyaical oetup. The second station tested the Align for Width and width Judgment cests but at two separated sites. No attempt was made to control the sequence of the stations; soldiers were assigned to the station and their sequence was not recorded. Within station One, soldiers followed a set patcern with half being tested on Ground Guide first and half on Left/Right Turn first. At Station Two, soldiers were always teated firot on Align for Width. Soldiers switched tanks between Station One and Station Two. All the tests in Phase One were conducted with the driver's hatch open.

None of the soldiers tested in Phase One was tested in Phase Two (Tactical tegts). Phase Two consisted of a circular course approximately 1.5 miles long. Each soldier remained on the a ame tank for all Tactical tests, and all were tested in the following sequence: 
- Main Gun Engagement

- M1ssile, Duck

- Hull Defilade

- Acceleration and Stopping

All Tactical teste were conducted with the driver's hatch closed; in fact, drivers kept the hatch closed during the entire testing circult.

The Obstacle/Judgwent test, Helght Judgment, was conducted in conjunction with the Tactical teste. Twenty-five of the 32 soldiers tested on the Tactical cests were tested on Helght Judgment. The majority of these 25 were cested before taking the Tactical test but no record of sequence was kept. Helght Judgment was conducted with the driver' hatch open.

Test Modifications. Tests were conducted as outlined in the 1ndividual test instructions, Appendix A, except ss discussed below.

- Follow Ground Gulde Signals. To determine if having a driver make a left tum or right tum while being ground guided in reverse made a difference in performance, the conduct of the test was modifled to have one-half of the soldlets make rlght tums and the remaining left tums.

- Left-Right Tum. The test was written to requite oldiers to make both a right tum and a left tum. During adoinistration, a ellght modilication was introduced that had one-half the soldlers aking the right tum flret and half the left tum flret.

- Control Tank During Main Cun Engagement. The test was designed to measure the percentage of time that the gunner was able to maintaln lay on the target during the engagement. Unfortunately, due to shortage of personnol, no gunners we re avallable and no data on this meaoure were gathered.

As the test of Control Tank During Maln Gun Engagedent was orginally set up, the driver was to be measured on his ablilty to malncaln $20 \mathrm{mph}$, h1s ablitty to keep the tront of the tank orlented in the diroctin of the target, and his announcing of avoiding an obstacle. Very early in the testing, problems were encuuntered with all three messures. The terraln was bumpy and at $20 \mathrm{rph}$, while no problens were encountered in the driver's compartment, the terrain was tou rough for the $r C / a c o r e r$ to manipulate stopwatch, scoresheets, and other scoring and control materials. Therefore, the speed requirement was 
deleted from the instructions (from this test and the Missile, Duck and Hull Defilade tests which followed) and the driver selected his own speed.

In the instructions the driver was told that he was to keep the front of the tank oriented on the target. The plan was to have the driver start the run at an approximate angle of 30 degrees off the target and then have the gun laid on the target during the run. Because of the terrain, iowever, only an angle of 5 degrees through 10 degrees could be obtained.

The terrain during the test also did not allow for an unavoidable obstacle necessitating an announced turn from the required path and no data were gathered on these measures. (Additionally, the requirement to announce turns is not doctrinally clear for the $\mathrm{Ml}$; it is probably a matcer of severity of the turn, and is dependent on crew requirements and training.) 
$\square$
$\square$

$\therefore$

$\because$

$r$

THIS PAGE INTENTIONALLY LEFT BLANK 
RESULTS

There are four major aspects of the results of the ML tank driving tests. The first concerns measurement reliability. In most cases measures of scorer agreement were obtained, with 80 percent agreement being the desired minimum standard of scorer agreement. 1 For some tests, agreement among several methods of obtaining evidence of the same skill is presented. The second aspect concerns utility of measures, based on their reliability and variability. The third aspect involves test revisions and recommendations for future testing based on the data and on informal observations. These three aspects are presented on the following pages for each of the nine tests. The fourth set of analyses of the results concerns the intercorrelations among the tests. These analyses follow the presentations of results for the individual tests.

Results for the Tests

Follow Ground Guide Signals. An experienced ( $\varepsilon-5$ cank conmander) ground guide directed examinees driving in reverse through the course. Observation and debriefing did not identify any instances of ground guideinduced barrier strikes or delays.

The data collected during the Ground Guide test were the time and number of barrier strikes before the turn, during the turn, and after the turn. Two observers counted the strikes, by location. The number of strikes recorded for each soldier by each scorer was quite low for both right turns and left turns. No more than two strikes were recorded for any soldier in all but one case. It was also the only case where more than one strike was recorded for any location. One of the scorers noted three batrier strikes for one soldier, while the other scorer recorded only two strikes. Therefore, the number of strikes was rescored to indicate whether or not any strikes occurred at each location. Two strikes in one location were recoded as a single strike.

\footnotetext{
1 Agreement percent was computed as the number of soldiers for whom scorers gave the same scores divided by the total number of soldiers scored by both scorers. The $80 \%$ standard was desired but surrounding testing factors were considertil when the agreement was near enough to make judgments about reliahility.
} 
Agreement between scorers was high for both right and left turns (Table 2). Full agreement--i.e., whether or not a strike occurred in each location-was 86.4 percent for both the right and the left turns. The high percentages were the result, at least in part, of the small number of strikes: scorers agreed that 15 (68.2 percent) soldiers on right turns and 13 ( 59.1 percent) soldiers on left turna had no strikes. For those soldiers where scorers agreed that at least one strike occurred--five soldiers on the right turn and seven on the left--full agreement on locations of strikes was 80 percent on right turns and 85.7 percent on left turns.

All points of measuring scorer agreement on the Ground Guide test met the $80 \%$ criterion. Information on strike location for those cases where scorers agreed- -19 cases each for the left and right turn-were considered in recommending test revisions.

The data suggest that left turns are more difficult than right turns (Table 3), but this observation must be tempered with the possibility that any difference in difficulty between right and left is quickly erased after initial brief practice. The location of the barrier strikes indicates that this might be so; the greatest difference is observed in number of strikes before the turn, with no difference in the number of strikes recorded during and after the turn. With more experienced drivers this initial problem probably should not exist. The time required to perform the test $d$ id not differ for right and left turns $(\underline{t}=.757, \underline{p}>.20)$, and was varied enough across soldiers (ranging from 55 to 193 seconds) to be useful in discriminating among proficiency levels (Table 4 ).

Because of the control problems in large scale administration of both right and left turn versions of the test, and the indications that the two are of comparable difficulty, testing of either turn is justified. Right and left testing with a more experienced group of drivers to see if the right and left similarities replicate is advisable. The low number of multiple strikes suggests the possibility of dropping the requirements that the scorer record the number and location of hits and instead record unly 
Table 3

Number of Barrier Strikes On

Follow Ground Guide Signals Test

\begin{tabular}{|c|c|c|c|c|}
\hline \multirow[b]{2}{*}{ Turns } & \multicolumn{4}{|c|}{ Number of Soldiers } \\
\hline & $\begin{array}{l}\text { Before } \\
\text { Turn }\end{array}$ & $\begin{array}{l}\text { During } \\
\text { Turn }\end{array}$ & $\begin{array}{l}\text { After } \\
\text { Turn }\end{array}$ & Overall \\
\hline \multicolumn{5}{|l|}{ Right } \\
\hline Strikes & 1 & 2 & 1 & 4 \\
\hline No Strikes & 18 & 17 & 18 & 15 \\
\hline \multicolumn{5}{|l|}{ Left } \\
\hline Strikes & 5 & 1 & 2 & 6 \\
\hline No Strikes & 14 & 18 & 17 & 13 \\
\hline
\end{tabular}

Table 4

Time Statistics

On Follow Ground Guide Signals Test

\begin{tabular}{llc}
\hline Turns & & Time $($ Seconds) \\
\hline Right & Mean & 102.0 \\
& S. D. & 30.8 \\
Left & Range & $55-153$ \\
& Mean & 109.9 \\
& S. D. & 37.3 \\
& Range & $56-193$
\end{tabular}

$a_{N=22}$. 
whether or not a strike occurred. However, this should only be done if the distances to be traversed are not substantially increased from the 60 feet used in this version of the test.

The test materials used a two by four inch board angled out from the ground to fender height to mark the pivot point and hold the engineer tape for the inside lane marker. This worked well except in those instances where the barrier strike occurred at the pivot point, resulting in repair or replacement of the board. These delays are interruptive and costly to a full test schedule; however, any other barrier arrangement must allow the tank side skirts to be within one to two inches of the barrier without interfering with the tracks.

Right and Left Turns. The toral number of barrier strikes was recorded in each category (Before, During, and After Turn) for the two turns for each soldier. A record was kept if the driver struck the barrier two, three, or more times, and the locations where the strikes occurred. Scorer agreement, on number and location of strikes, was 88.6 percent for both the $r$ ight and the left turn (see Table 5). As with the Ground Guide test, both scorers recorded no strikes for a majority of the soldiers: 31 ( 70.5 percent) on the left and 25 ( 56.8 percent) on the right. For those soldiers where scorers agreed that at least one strike occurred--11 soldiers on the left turn and 17 on the right--full agreement on location and number of strikes was 72.7 percent on the left and 82.4 percent on the right.

One soldier performing the left turn and one performing the right turn scored three strikes; in both cases the strikes occurred in the portion of the turn before the pivot. Scoring of strikes in each category (Before, During and After Turn) should be reduced to No Strikes, One Strike, and Two or More strikes and future scorers should not be tasked with counting strikes over two, since so few soldiers had more than two strikes.

For the cases where scorers agreed on location and number $(0,1,2$ or more) of strikes--39 on the left and 40 on the right (Table 6)--the turn itself appears tn be the most difficult portion of the test, in judgment, in controlling the tank, or both. The right turn also appears to be inore 
$\check{\check{\Gamma}}$

a

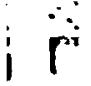

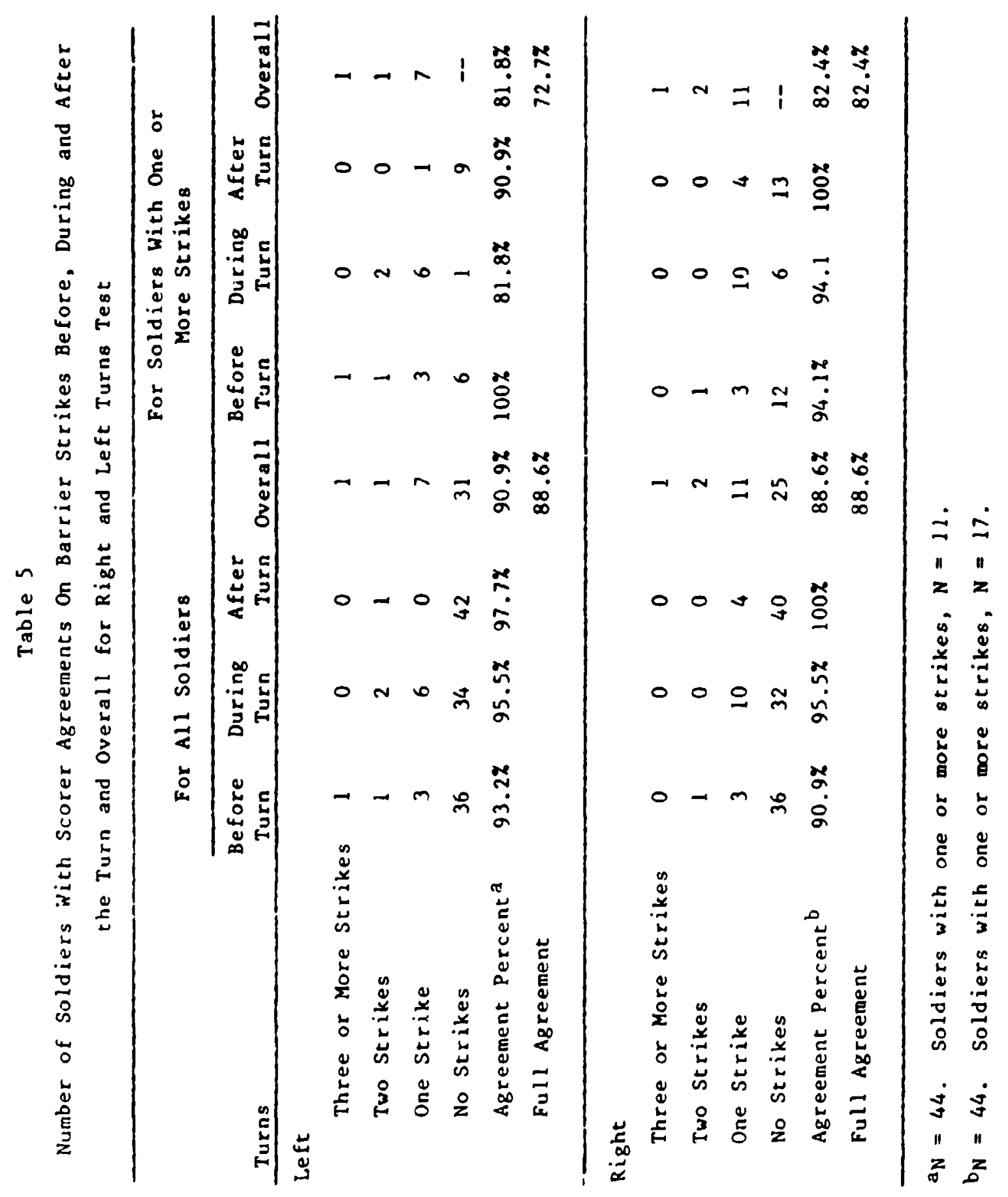


difficult-more soldiers had strikes during the right turn than during the left. At the same time, the left turn resulted in a somewhat wider turn radius (Table 7). The difference in radius is not statistically significant $(\underline{t}=1.37, p)$. 10) but it appears that drivers had some difficulty in judging their position for the turns, and the difficulty was different for left and right: more strikes on the right, wider turn on the left. The reason for the difference in performing the turn between right and left is not immediately obvious. (The Ml driver's hatch is on the driver's right when open.)

The times for the two turns are not different, but for both turns the longer times were associated with shorter turn radii, while short $t$ imes occurred for both long and short turn radii. It is not know whether this will replicate with more experienced drivers, however, it is recommended that both right and left turns be retained in future testing.

All these measures--location of strikes, length of turn radius, and time--have suficient variance, in addition to their usefulness as measures of driving performance, to be included in future testing.

The same problems with the pivot point durability described in the Ground Signals Test applied here as well.

Align Tank for widch. Several measurements of width alignment were explored during the testing. The measures included whether each barrier strike was brief or sustained, where on the tank the strike occurred (front, side, or rear), and in which quarter of the passage the strike occurred. The scorer agreement in each of these areas is shown in Table 8 .

Scorer agreemeni on whether or not a hit occurred and the number of hits occurring was rather good- -97.7 percent on the left and 86.4 percent on the right. Multiple strikes (two or more) were recorded only two times by the scorers, however, and on only one of these were both scorers in agreement that a multiple hit took place. No more than two strikes were recorded 
Table 6

Number of Barrier Strikes On Right and Left Turns Test

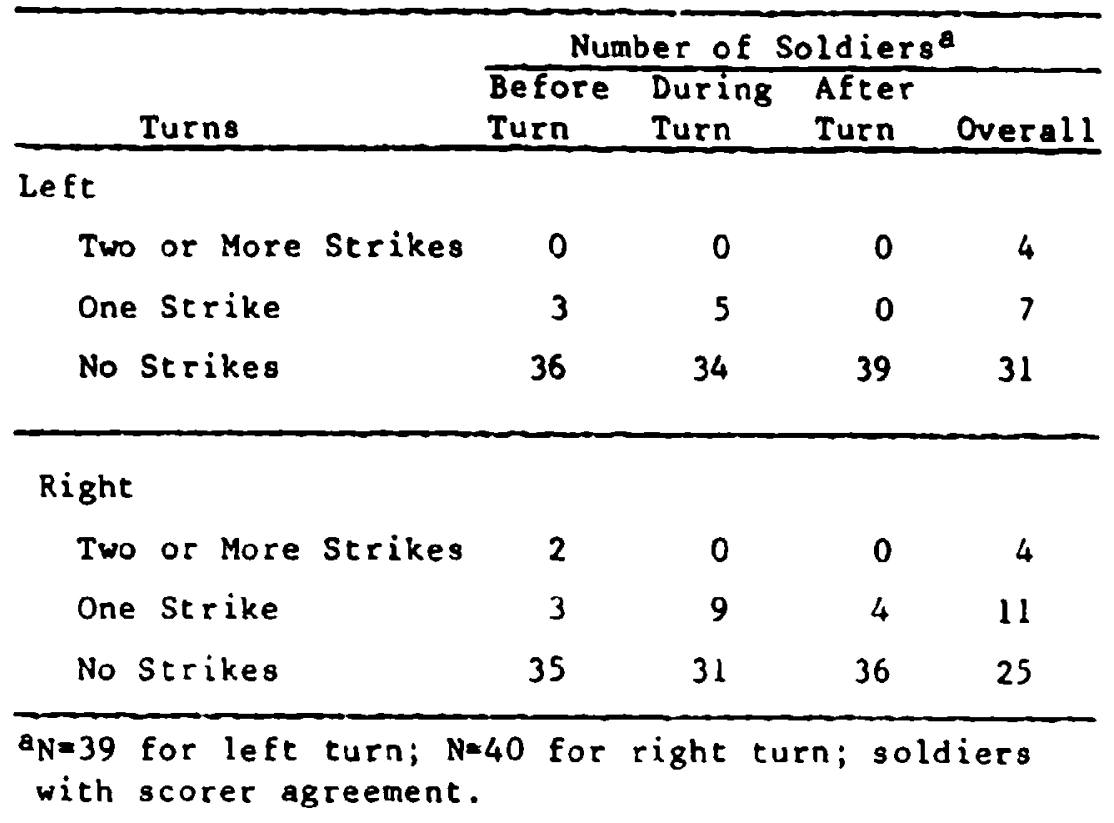

Table 7

Turn Radius and Time Statistics

on Right and Left Turns Test

\begin{tabular}{cc} 
Turn & Time \\
Radius & (Seconds) a \\
\hline
\end{tabular}

Mean 19'6" 57.1

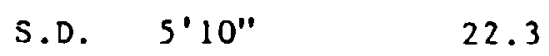

Range $12^{\prime} 2^{\prime \prime}-31^{\prime} 6^{\prime \prime} \quad 24-106$

\begin{tabular}{lcc} 
Mean & $17^{\prime} 9^{\prime \prime}$ & 61.7 \\
S.D. & $5^{\prime} 6^{\prime \prime}$ & 24.0 \\
Range & $10^{\prime} 6^{\prime \prime}-33^{\prime} 6^{\prime \prime}$ & $29-133$ \\
\hline
\end{tabular}

$a_{N}=39$ for left turn; $N=40$ for

right turn; soldiers with scorer agreement. 
Table 8

Number of Soldiers with Scorer Agreements on Number of Strikes, Duration of Strikes, Porcion of Tank, and Quarter of

Passage for Align Tank for Width Test

\begin{tabular}{|c|c|c|c|c|}
\hline Measures & $\frac{\text { For All }}{\text { Left }}$ & $\frac{\text { Soldiers }}{\text { Right }}$ & $\begin{array}{c}\text { For Soldiers } \\
\text { One Or More } \\
\text { Left } \\
\end{array}$ & $\begin{array}{l}\text { With } \\
\text { Strikes } \\
\text { Right }\end{array}$ \\
\hline \multicolumn{5}{|l|}{ Number of Strikes } \\
\hline Two Strikes & 0 & 0 & 0 & 0 \\
\hline One Strike & 7 & 6 & 7 & 6 \\
\hline No Strikes & 36 & 32 & -- & -- \\
\hline Agreement Percent & $97.7 \%$ & $86.4 \%$ & $100 \%$ & $75 \%$ \\
\hline N & 44 & 44 & 7 & 8 \\
\hline \multicolumn{5}{|l|}{ Duration of Strikes } \\
\hline Sustained & 3 & 6 & 3 & 6 \\
\hline Brief & 1 & 0 & 1 & 0 \\
\hline No Strikes & 36 & 32 & -- & -- \\
\hline Agreement Percent & $95.24 \%$ & $86.36 \%$ & $66.7 \%$ & $75 \%$ \\
\hline $\mathbf{N}$ & 43 & 44 & 6 & 8 \\
\hline \multicolumn{5}{|l|}{ Portion of Tank } \\
\hline Eront & 5 & 1 & 5 & 1 \\
\hline Rear & 0 & 0 & 0 & 0 \\
\hline Side & 0 & 3 & $c$ & 3 \\
\hline No Strikes & 36 & 32 & -- & - \\
\hline Agreement Percent & $93.2 \%$ & $81.8 \%$ & $71.4 \%$ & $50 \%$ \\
\hline $\mathrm{N}$ & 44 & 44 & 7 & 8 \\
\hline \multicolumn{5}{|l|}{ Quarter of Passage } \\
\hline Strike/ First & $0 / 43$ & $3 / 39$ & $0 / 7$ & $3 / 7$ \\
\hline \multirow{3}{*}{$\begin{array}{r}\text { No Strike Second } \\
\text { Third }\end{array}$} & $1 / 40$ & $2 / 39$ & $1 / 4$ & $2 / 7$ \\
\hline & $3 / 39$ & $2 / 39$ & $3 / 3$ & $2 / 7$ \\
\hline & $5 / 37$ & $4 / 35$ & $5 / 1$ & $4 / 3$ \\
\hline No Strike & 36 & 32 & -- & -- \\
\hline Agreement Percent & $93.0 \%$ & $86.0 \%$ & $66.7 \%$ & $65.5 \%$ \\
\hline $\mathrm{N}$ & 43 & 43 & 5 & 8 \\
\hline
\end{tabular}


in a multiple strike. When agreement percentages included soldiers with no strikes, the results were very high. Agreements were much lower, however, for only those soldiers on whom a strike was scored.

The low scorer agreement in some of these areas may result from the method. The passage was relatively short (approximately 60 feet) and difficult to divide into quarters, and the quarter distinction was difficult to ascertain in sustained strikes. The distinction between a front of tank strike and a side tank strike was difficult. Many strikes occurred at the exit end of the barrier where it was difficult to determine whether the strike was brief or sustained and to determine exactly where on the tank the strike occurred. A number of times a driver struck a barrier sipport or the engineer cape became entangled in the tracks so it was virtually impossible to score accurately the type and number of hits. For these reasons it is recomended that the strike descriptive measures and number of strikes be dropped from subsequent applications of the test, and scoring concentrate on whether or not a strike occurred. This deletion should also simplify the scoring process.

The $t$ ime requited for the test ranged from 22 to 130 seconds, which does not appear to be an immediately useful evaluation measure. Operationally, navigation of a natrow passage dictates some caution on the part of the driver and speed should not be emphasized. At some point the time expended becomes excessive, but a 60-second variation has little operational impact. Time is reported here to assist in the planning of future tests; because of difficulty in interpreting the time factor it is recomended that it be dropped.

The drivers were required to make a turn into the barrier passage to avoid having the tank already lined up or almost lined up with the pasage. Based on observations, very few drivers had problems lining up the cank after the turn for entry into the passage. If test conditions in subsequent application preclude the turn it would probably make little difference in the outcome of the test, particularly if more experienced drivers were tested, although intuitively the retention of the turn is attractive. 
One problem was encountered with stability of the engineer tape barrier. The tape was braced at the midpoint with an upright, but even a mild wind blew the tape in on one side and out on the opposite side. Scorers compensated by using the upright stakes as a line of aight roference and ignoring the actual position of the tape. However, it is unknown how much this movement of the barrier affected drivers. One way of corapensating for this is to erect more uprights, but rebuilding slows test edministration when upright:s are knocked down.

Width Judgment. Only one scorer gathered data for the width judgment test. An incorrect decision was scored if a driver tried to drive through the 144 inch gate or bypassed the 157 inch or 169 inch gates. As shown in Table 9, there were as many soldiers with incorrect decisions on the 169 inch gate as on the 157 inch gate, but the judgment bout the 144 inch gate was significantly worse.

Table 9

Number of Soldiers with Correct Decisione By Gate and By Number of Correct Decinion. For Width Judgment Teat

\begin{tabular}{lll} 
Gate Width & $\begin{array}{l}\text { Cortect } \\
\text { Decision }\end{array}$ & $\begin{array}{c}\text { Number Correct } \\
\text { (Nous) }\end{array}$ \\
\hline 169 inches & Attempt & $35(81.4 \%)$ \\
157 inches & Attempt & $36(83.7 \%)$ \\
144 inches & Bypass & $31(2.1 \%)$
\end{tabular}

Correct Decisions After All Gates

\begin{tabular}{cr}
$\begin{array}{c}\text { Number of } \\
\text { Correct Decisions }\end{array}$ & $\begin{array}{c}\text { Number of } \\
\text { Soldiers }(\mathrm{N}=43)\end{array}$ \\
\cline { 2 - 2 } & $22(51.2 \%)$ \\
Two & $15(35.2 \%)$ \\
& $6(14.0 \%)$ \\
\hline
\end{tabular}


The soldier was also scored on whether or not he cleared the gate, if he attempted it (see Table 10). Although the total number of times that the driver did not clear passable gates was small (11), seven of these occurred on the 169 inch gate and only four on the 157 inch gate. Drivers may have tried to navigate the wider gate faster or with less care. Out of the 70 possible opportunities for strikes, when soldiers attempted the passable gates, strikes occurred in only 15.7 percent of the cases (11 strikes). This number of etrikes is low and could be expected to decresse with roore experienced drivere.

Table 10

Number of soldiers With Gate serikes By

Gate and By Nimber Of Gates struck for

Width Judgment Teot

\begin{tabular}{|c|c|c|c|}
\hline Cate & Width & $\begin{array}{l}\text { Number of } \\
\text { Attempts }\end{array}$ & $\begin{array}{c}\text { Number of } \\
\text { serikes }\end{array}$ \\
\hline 169 & Inches & 35 & $(20.0 \%)$ \\
\hline 157 & inches & 35 & $(11.4 \%)$ \\
\hline
\end{tabular}

Number of Strikes Over All Gates

\begin{tabular}{lr}
\hline $\begin{array}{c}\text { Number of } \\
\text { Catee struck }\end{array}$ & $\begin{array}{c}\text { Number of } \\
\text { Soldiers }(N-31)\end{array}$ \\
\hline Two & 0 \\
One & $9(29.0 \%)$ \\
None & $22(71.0 \%)$ \\
\hline
\end{tabular}

Because so few gate otrikes wera recorded, the usefulness of this variable to questionable, alchough gathering information on gates itruck is not coetly and did not oppeer to interfere with other ecoring requitemente. The variatlo should be retained, at leas untll further teating pruildea more Information for a firinar decision.

The time requited to perform the Width Judgment teat ranged from 6 areconda to 102 seconde. Because this is largely a function of the ooldier'. decisions to bypass gates or attempt to pasa through, and becaune time to perfurin in wot a critical element, this measura nhould be deleted. 
Height Judgment. For this test, two scorers--a ground observer and the tank comander--scored whether the soldiers bypassed or attempted to pass through each of the six gates. For five of the gates, the correct decision was to pass through, and for one gate the correct decision was to bypas. Only 25 soldiers were teoted on height judgment, and complete data were obtained for 18 of the 25 soldiers. Seven soldiers had incomplete data because of conflicting demands for the TC/scorer's attention.

Scorers agreed on the number of correct decisions for 16 soldiers (rable 11), representing 88.9 percent of soldiers with complete data. However, scorers were reliable on only 64 percent (16 of 25 ) of the scores; the 8 occasions involving 7 soldiers where data were not recorded represent unceliability among the scorers. For one of those sixteen agreements on the number of correct decisions, scorers did not agree on the gates where correct decisions were made. Thus scorer reliability is reduced to 60 percent.

Table 11

Number of Soldiers With Scorer Agreements By Gate and By Number of Correct Decisions For Height Judgment Test

\begin{tabular}{|c|c|c|c|c|c|}
\hline $\begin{array}{c}\text { Number Of } \\
\text { Correct Decisions } \\
\end{array}$ & $\begin{array}{l}\text { Number of } \\
\text { Agreementsa }\end{array}$ & $\begin{array}{c}\text { Gate } \\
\text { Height } \\
\end{array}$ & $\begin{array}{l}\text { Agreem } \\
\text { Correct } \\
\text { Decision }\end{array}$ & $\begin{array}{l}\frac{\text { ntsb }}{\text { Incorrect }} \\
\text { Decision }\end{array}$ & $\begin{array}{r}\text { Percent } \\
\text { Agreement } \\
\end{array}$ \\
\hline $\operatorname{six}$ & 4 & 119 inches & 21 & 3 & $96.0 \%$ \\
\hline Five & 4 & 118 inches & 19 & 6 & $100 \%$ \\
\hline Four & 4 & 117 inches & 18 & 5 & $92.0 \%$ \\
\hline Three & 3 & 116 inches & 13 & 5 & $100 \%$ \\
\hline \multirow[t]{2}{*}{ Two } & 1 & 115 inches & 14 & 9 & $95.8 \%$ \\
\hline & & 114 inches & 15 & 12 & $100 z$ \\
\hline Agreement Percent & $88.9 \%$ & \multicolumn{2}{|c|}{ Full Agreement } & & $83.3 \%$ \\
\hline
\end{tabular}

$a_{\mathrm{N}}=18$.

$\mathrm{bN}=25$. For 116 inch Gate, $N=18$. For 115 inch Gate, $N=24$. 
Scorer unreliability stemed, at least in part, from the use of the tank commander as a scorer. The TC was required to operate with the hatch in the protected open position, which decreased visibility and hampered the manipulation of scoresheets, stopwatch and pencil. The TC was also required to divide his time between scoring and control of the driver, with driver control his paramount responsibility.

During the testing only one 8 ate was impassable $(114$ inches). This gate was switched with one other after approximately every fourth examinee. However, the switching was not random--the impassable gate was always either Gate 1 or Gate 4 .

Considering only those cases, on each gate, where scorers agreed on the soldier's decision, the relative difficulty of the decisions for the six gates is shown in Table 12. The number of correct decisions forms a consistent ascending pattern. But of the 15 soldiers on whom scorers agreed on the decision for every gate, 8 soldiers ( 53.3 percent) displayed a pattern of decisions in which they never decided to pass through a gate which was smaller than a gate they bypassed. So, while the collective discriminations appear to be consistent, the actual individual patterns are not.

Table 12

Number of Correct Decisions By Gate

For Height Judgment Test

\begin{tabular}{lcccc}
\hline Gate Height & $\begin{array}{c}\text { Number of } \\
\text { Soldiersa }\end{array}$ & $\begin{array}{c}\text { Number } \\
\text { Correct }\end{array}$ & $\frac{\text { Percent }}{87.5 \%}$ \\
\cline { 2 - 3 } 119 inches & 24 & & 21 & 87 \\
118 inches & 25 & 18 & $76.0 \%$ \\
117 inches & 23 & 13 & $72.2 \%$ \\
116 inches & 18 & 14 & $60.9 \%$ \\
115 inches & 23 & 13 & $52.0 \%$ \\
114 inches & 25 & & \\
\hline
\end{tabular}

asoldiers with scorer agreements. 
Scorers were not in full agreement on the times recorded. For the ground observer, times ranged from 46 to 159 seconds; for the tank rommander, the times were from 71 to 230 seconds. The correlation between the two is significant $(\underline{I}=.673, P<.001)$, but the variance is too high to be acceptable. Again, the TC workload affected time correlations. Scorer training emphasis on how to handle the timing of out-of-the-ordinary driver performance, such as when the soldier hesitates after the final gate before reaching the stop foint or when drivers have false starts, might improve the agreements.

This test drew the most negative reaction from military scorers and observers fron the OSUT battalion cadre of all the tests tried out. Their main negative reaction was that the judgment required in the test was unrealistic--that on the job no similar driver reaction is expected or even desired. (It is worth noting that similar objections were not raised with other tests in which the tested driver requirements do not match job conditions. In many of the cests involving judgments the requirement on the job does not call for the driver to make decisions unassisted. Why this test has been singled out for comment is not clear; perhaps it is a matcer of the degree of driver involvement. Height judgment is primarily a TC responsibility; the other tests are at least partially a driver's responsibility. This, however, is only conjecture, as during the Ml Driver Survey from which the tasks were selected no objections to this as a driver activity were noted.)

This test is the most difficult to set up of all tests used. Approximately 12 man hours were required for setup, which did not include time required for filling sandbags to secure the upright posts. The test is also difficult to administer in that personnel and time are required to change the height of the barriers and to replace knocked-down barriers.

Two problems which could occur with future tests surfaced during the tryouts. The first of these concerns the impassable gate. Because the colerance is very close ( 114 inches) a very slight disturbance in ground contour allows the tank to pass under the 114 inch barrier, which occurred for at least chree of the examinees. Likewise on the close, passable 
barriers ( 115 inches and 116 inches) a slight buildup of dirt causes a barrier strike. Every effort was made to minimize this by "tracking" the course repeatedly before the test but the course height still changed with each run of the circuit--and, of course, the change was uneven, so remessuring before each run, besides being impractical, does not solve the problem. The only solution would be to run on a dry, hard surface (or paved or concrete) course.

The second problem did not occur during testing but was observed during the aforementioned tracking runs of the course using an experienced driver. When the $M l$ is driven fast and the terrain is rough, the tank can bounce up and strikes otherwise passable overhead barriers. Thus measurement for this test should not only include the judgment factor but also may have to consider the skill factor in actually negutiating under the obstacle.

As originally conceived, this test would be combined with the width judgment test. The driver would be presented with a series of rectangles in which the height and width would vary but the total "open" footage would remain relatively constant. This method was not practical because of the difficulty in constructing and stabilizing upright posts ten feet tall without using interior space. If this combination testing is to be used a more sophisticated approach to barrier construction will have to be devised.

This test should be reanalyzed before it is tested again. One of the considerations should be whether, as presently outlined, the distinctions between barrier hejghts are too fine. Only five inches total separated the impassable barrier from the highest barrier. It may be that divers should be required to make grosser distinctions; e.8., those heights that can definitely be cleared, those heights that definitely rannot be cleared, and those heights when the driver must have TC assistance for a decision. Translating these classes into specific measures is, of course, $a$ distinct problem. However, as presently constructed it is difficult to say that a driver who bypasses the 115 inch barrier, for instance, is "wrung," whereas on the job he might be encouraged to take this cautious approach. In the final analysis the test must remain consistent with field procedure if it is to be used on a wider scale. 
Control Tank During Main Gun Engagement. Two measures of "steady platform" were employed in the test. One was the percentsge of $t$ ime in which the gunner was able to maintain a lay directly un the target, and the other was the number of times the transmission shifted during the engagement. Unfortunately, no data on the first measure were gathered because a sortage of test personnel precluded having any gunners.

The other measure (transmission shifts) was also disappointing in that, because of scorer misunderstanding, data were gathered from only eight soldiers. However, even these sparse data, as shown in Table 13, hold some promise, by virtue of the variability, that this measure may potentially provide a good quantitative measure. Both have oufficient potential to be retained in future testing.

Table 13

Number of Soldiers By Number of Transmission

Shifts On Control Tank During Main Gun

Engagement Test

\begin{tabular}{ccc}
$\begin{array}{c}\text { Number of } \\
\text { Transmission Shifts }\end{array}$ & $\begin{array}{c}\text { Number of } \\
\text { Soldiers }\end{array}$ & $\begin{array}{c}\text { Percent } \\
(\mathrm{N}=8)\end{array}$ \\
\hline One & 1 & $\frac{12.5 \%}{62.5 \%}$ \\
Two & 5 & $62.0 \%$ \\
Four & 2 & 25 \\
\hline
\end{tabular}

${ }_{\text {Average }}=2.5$ shifts.

Engagment times ranged from $12-65$ seconds with an average of 35 seconds. At $20 \mathrm{miles}$ per hour, as originally planned, the engagement probably requires 15 to 20 seconds.

As the test was originally set up, the driver was also to be scored on his ability to keep the front of the tank oriented in the direction of the target and his announcing of the avoidance of an obstacle. As discussed earlier, conditions were such that tank orientation was not difficult to 
maintain, and reaction to an obstacle could not be tested. No variation among drivers in orienting the tank was recorded; all drivers were scored as having oriented the front of the tank towards the enemy.

In sumation of these three measures--ability to maintain 20 miles per hour, tank orientation, and reaction to obstacle--it is recomended that the 20 miles per hour speed be maintained as a requirement in future test applications with the understanding that cerrain may force modifications. The requirement to turn the tank so that the front is facing the enemy should also be retained but only if the terrain permits measurement. The obstacle requirement should be dropped. It is difficult to set up and, if run at 20 miles per hour, requires too many diverse measures in a very short time and represents a new and unevaluated threat to scorer reliability.

Acceleration and Stopping. The measurements taken consisted of tire from start to stop and distance over or short of the stop line. The average time to cover the 60 meter distance was 24 seconds and times ranged from 8 seconds to 48 seconds. A measurement was made from the stop line to where the cank actually stopped. (During testing, drivers were not allowed to stop and then move forward to the line--they were stopped where movement of the tank first halted.) It is of some significance that none of the 32 drivers exceeded the stop line boundary. The average distance short of the line was 9 feet and 3 inches with the range from 0 to 40 feet. Two drivers stopped exactly on the line.

The stop line was also marked off with right and left boundaries at a width of 20 feet, but measurement indicated that no one exceeded the right or left limits. If even novice drivers have no problems maintaining the cank within these limits it is recommended that for future tests the limits be decreased to closer to the 12-foot tank width (perhaps 15 feet) or that this measure be dropped, with the latter choice being favored.

TC/scorers also made subjective ratings of both the movement (acceleration) and the stopping (Table 14). Because neither of these subjective evaluations relates directly to speed, no correlation was computed with sctual times to traverse the course. Although there might be some 
diagnostic value in the stopping evaluation, there does not appear to be enough variation in the acceleration evaluation to warrant its retention (the situation is unlikely to improve among experienced drivers) and it should be deleted. If the stopping evaluation is retained, it should be condensed into three categories (Smooth, Jerky, Abrupt).

Table 14

Number of Soldiers By Acceleration Rating

and Stopping Rating on Acceleration and

stopping Test

Rating $\begin{aligned} & \text { Number of } \\ & \text { Soldiers Percenta }\end{aligned}$

Acceleration

Smooth

28

$90.3 \%$

Jerky (Acceptable)

3

$9.7 \%$

Jerky (Unacceptable)

0

$0.0 \%$

\section{Stopping}

$\begin{array}{lrr}\text { Smooth } & 11 & 35.5 \% \\ \text { Jerky } & 13 & 41.9 \% \\ \text { Too slow } & 2 & 6.5 \% \\ \text { Abrupt } & 5 & 16.1 \%\end{array}$

$8_{N}=31$

React to TC Command (Missile, Duck). OSUT drivers were expectes to have problems with the concept and execution of this maneuver; therefore, they were briefed before the run on exactly what the manuever required. While many did have problems, particularly in reacting, performance varied from poor to good. TC gave subjective ratings on the timing of the move and the speed of the move, once the driver reacted (Table 15). 
Table 15

Numbers of Soldiers By Ratings of Speed and Timing on Missile, Duck Test

\begin{tabular}{lccc}
\hline & \multicolumn{3}{c}{ Timing Rated } \\
\cline { 2 - 4 } Speed Rating & Immediate & Delayed & Total \\
\cline { 2 - 4 } Fast Enough & 10 & 9 & 19 \\
Too Slow & 1 & 9 & 10 \\
\hline Total & 11 & 18 & 29 \\
\hline
\end{tabular}

The majority of OSUT drivers hesitated in their reaction to the command (at least in the TC evaluation). Of those whose reaction was delayed, half then noved at a fast enough speed. Of the 11 soldiers who reacted immediately, all but one were then judged to move fast enough.

The lack of immediate reaction is also apparent in the times recorded. OSUT drivery required an average of 33.6 seconds to get into position, with a range of 12 to 61 seconds. In tryouts of the cest, experienced drivers (the TC/ocorers) took between 10 and 15 seconds from the point where the command was given to the defilade position; however, the slowness of the OSUT drivers in reacting was not unexpected. During testing TC were also asked to note in the scoresheet "Remarks" scction any deviation from the expected performance. TC noted that 8 drivers ( 24 percent) either did not stop or could not determine the position and that another 9 drivers (27 percent) took up an improper position. In at least three situations they took a position on the left ide of the course instead of the right side from which the simulated missile launch occurred. Although the drivera were told at least twice from which side the missile would be coming, ome either did not understand this or did not comprehend the significance of the launch location.

The subjective TC rating were examined to compare subjective evaluations of time-related events with actual times to see if a more objective evaluation of seemingly subjective criteria could be identified. As shown in Table 16, for the 27 soldiers for whon ratings and times were recorded, both subjective evaluations are otrongly associated with actual times. Even 
though highly correlated, the TC evaluations are probably of little quantitative value currently, and more in-depth study of the correlation between the subjective ratings and objective measures is needed before a use can be determined. However, they should be retained for future test applications, since they provide good diagnostic information and help focus training emphasis in some test applications.

Table 16

Actual Test Times of Soldiers By Levels of Speed and

Timing Ratings On Missile, Duck Test

\begin{tabular}{|c|c|c|c|c|}
\hline \multirow[b]{2}{*}{ Rating } & \multirow[b]{2}{*}{$\underline{N}$} & \multicolumn{3}{|c|}{ Time (Seconds) } \\
\hline & & Mean & St. Dev. & Difference \\
\hline \multicolumn{5}{|l|}{ Speed } \\
\hline Fast Enough & 17 & 27.6 & 14.3 & 18.2 seconds \\
\hline Too slow & 10 & 45.8 & 15.1 & $t=3.13, p<.01$ \\
\hline
\end{tabular}

Timing

$\begin{array}{llllc}\text { Imnediate } & 11 & 26.1 & 13.6 & 13.9 \text { seconds } \\ \text { Delayed } & 16 & 40.0 & 17.0 & \underline{t}=226, \underline{p}<.05\end{array}$

Two scorers were used on the ground at a distance of approximate:y 100 meters from the hide position. They recorded three measures of exposure: a descriptive evaulation (maintained concealment, intermittent exposure, exposed throughout), a count of tank markings that were visible, and a mark on a drawing of the tank to indicate the portion exposed (see scoresheet in Appendix A).

On the first measure (Table 17), overall the acorer agreement was 77.4 percent. Two of the disagreements were between the first two responses (maintained concealment and intermittent exposure), three were between intermittent and exposed throughout, and two were full disagreements, between maintained concealment and exposed thro'ghout. There may have been some confusion on the intent of this messurement. Some drvers were expected to pull into position iritially, evaluate the position and then make position 
adjustments based on that evaluation. This action seldom occurred and the ground scorers may have had problems determining exactly when the driver was in position. The descriptive evaluation did not dis"riminate correct from incorrect performance, although it is a fairly reliable description of what the driver did. Except for Exposed Throughout, the actions described are neither right nor wrong. Unless future tests with more experienced drivers reveal that position adjustment occurs with some frequency, this measure should be dropped.

Table 17

Number of Soldiers with Scorer Agreements on Evaluation of Amount of Tank Exposure on Missile, Duck Test

\begin{tabular}{lc}
\hline Evaluation & $\begin{array}{c}\text { Number of } \\
\text { Agreements }\end{array}$ \\
\cline { 2 - 2 } Maintained Concealment & 7 \\
Intermittent Exposure & 6 \\
Exposed Throughout & 11 \\
Agreement Percent a & $77.4 \%$ \\
\hline
\end{tabular}

$a_{N}=31$.

The second and third ground scorer measures were measures of the same thing using different methods of recording. For one of these measures, test tanks were marked across the front slope, side skirts and turret glacis with $1 / 2$ inch yellow adhesive tape spaced 6 inches apart. There were three tape segments on the hull side skirts, three on the turret, and two on the front slope. The tape segments extended approximately 5 feet back on the skirts and to the rear apex of the frontal glacis on the turret.

The intent was to give scorers a handy, simple reference for scoring what they could see of the tank by recording the number of tape lines they observed on the hull and on the turret. The most frequent agreements were that the tank was fully exposed ( 3 hull tapes, 3 turret tapes) or fully concealed (no tapes visible) (Table 18). Of the 31 soldiers with complete 
Table 18

Number of Soldiers With Scorer Agreements on Patterns of Tapes Visible For Missile, Duck Test

\begin{tabular}{ll}
\hline Measures & $\begin{array}{l}\text { Number of } \\
\text { Agreement } a^{a}\end{array}$ \\
\hline
\end{tabular}

Tapes Visible, Hull and Turret

No Hull Tapes, No Turret Tapes

5

No Hull Tapes, One Turret Tape

1

No Hull Tapes, Three Turret Tapes

4

Two Hull Tapes, Three Turret Tapes

1

Three Hull Tapes, Three Turret Tapes

Full Agreement Percenta

$67.7 \%$

Tapes Visible, Hull Only

No Tapes

15

Two Tapes

1

Three Tapes

10

Hull figreement Percenta

$83.9 \%$

Tapes Visible, Turret Only

No Tapes

One Tape

1

Three Tapes

Turret Agreement Percenta

$77.4 \%$

$a_{N}=31$. 
scorers agreed that 5 ( 16 percent) had no tapes visible, and 10 ( 32 percent) had all tapes visible. The total number of agreements was 21 or 67.7 percent.

Scorer agreement was slightly better for counts of hull tapes than for the turret evaluation. For hull tapes, scorers agreed on 15 cases of no tapes visible and 10 of all three visible, with total agreement of 26 ( 83.9 percent). For turret tapes there were 5 agreements on no tapes and 18 on all capes, and a total of 24 agreements ( 77.4 percent).

As a supplementary means of measuring exposure, scorers were provided a two-view diagram of an Ml tank (see Scoresheet, Appendix A) and told to mark with a line the portion of the tank they could see. Subsequently a grid was prepared (see Figure 1) which divided the tank into seven segments. (Only the right side profile of the tank was used; because of the position of the tank no entries were made on the left side profile). This overlay was applied to each of the scorer's markings. If the scorer's marking included any part of a segment the entire segment was considered exposed. An analy$s i s$ of the exposure and concealment agreemelt by segment is shown in Table 19.

Table 19

Number Of Soldiers with Scorer Agreements on Tank Segments Exposed Using Profile Overlay Method For Missile, Duck Test

\begin{tabular}{lccc}
\hline & \multicolumn{2}{c}{ Number of Agreements } & \\
\cline { 2 - 3 } Segment & $\frac{\text { Exposed }}{18}$ & $\frac{\text { Concealed }}{2}$ & $\begin{array}{c}\text { Agreement } \\
\text { Percent }\end{array}$ \\
\cline { 1 - 2 } 1. Gun Tube & 21 & 9 & $64.5 \%$ \\
2. Turret Gun Mount & 10 & 18 & $96.8 \%$ \\
3. Front Slope & 24 & 4 & $90.3 \%$ \\
4. Turret Side Glacis & 10 & 19 & $90.3 \%$ \\
5. Side Hul1, Front & 25 & 5 & $93.5 \%$ \\
6. Bustle Areat & 10 & 18 & $90.3 \%$ \\
7. Side Hull, Rear & & & \\
\hline
\end{tabular}

$a_{N}=31$. 
The greatest disagreement was whether the gun tube (segment 1) was exposed or not. The scorer's main concentration is probably on the bulk of the tank and the gun tube is often ignored, enpecially if the mein body of the tank is concealed. Additionally, the gun tube is the smallest of all the separate segements evaluated. Agreement on the remeining segments was quite good.

The agreement by segment: atterne is shown in Table 20. Scorers agreed on attern of all seven segments in only litele over hall of the cases (i6, or 52 percent). One agreement was that the tank was fully concealed, five indicated that the full turret only was exposed, and ten agreed that the full tank was exposed. In the noxt column the agreement was computed when the only area of dieagreement was whether the gun tube was exposed or not. The final agreement index excluded, in addition to the gun tube only disagreements, those cases where the dinagreement was on a single adjacent segment (because a close inspection of the ratinge showed many cases where the line the ocorer drew could judgmentally be called in or out of the cegment).

Table 20

Number of Soldiers With seorer Agreements on Three Pacterns of Tank Segmence Exposed U.ing Profile Overlay on Mieslle, Duck Test

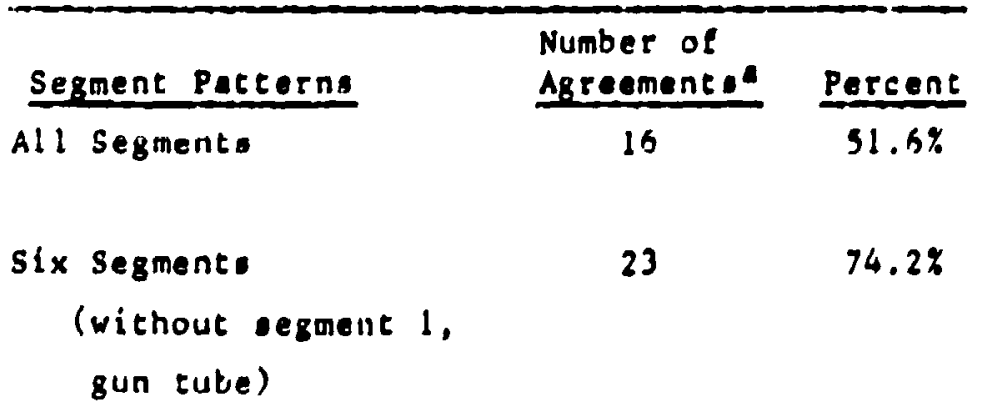

Six Segments

(within one adjecent segment)

$a_{N}=31$. 
The comperison in Table 20 is presented to suggest what increased -corer training might achieve in such sreas as attention to the gun tube. Additionally, the divioion of the task into the seven segmente was someuhat erbitrary. Pewer segments vould undoubtedly give greater scorer agreemente although with a decrease in detail.

A comparieon of the two methods of measuring exposure does not provide any clear guidance tor lucure application. In thle taek the profile overlay sugsests one adventege in that le provides more detalled exposure definition. Table 21 showe a comparison of the two methode using three categories of exposure: cotally cuncealed, hull concealed and turret exposed, and totally exposed. The tape method appears to allow more leewoy, with over one-fourth of the coldiere concested, and approximately hall cotally exposed. By concrast, the proflle method cleselfled well over hall uf the -oldiere es tully exposed. Hovever, of the 14 ooldlere for whom there were scorer agrecmente on both the tape method and the profile method, the two wethods vere in full egreoment in categorizing the soldiers es exposed, partiully exposed, or concealed.

\section{Table 21}

Number of Soldiers in Three Categorice of Tank Exposurs Uaing Tapo Mathod and Profile Overlay Method of Detorminitig

Tank Expoeure on Miselle, Duck Test

\begin{tabular}{lrc}
\hline Outcone & $\frac{\text { Tape Methoda }}{5(26.3 \%,}$ & $\frac{\text { Profile Ouerleyt }}{1(6.2 \%)}$ \\
Tank Totally Concealed & $4(21.1 \%)$ & $5(31.2 \%)$ \\
Hull Concalied/Turret Exposod & $10(32.6 \%)$ & $10(62.3 \%)$ \\
Tank Totally Exposed & &
\end{tabular}

ANe19 ooldlers wlth ocorar agreament.

$b_{N}-16$ ooldiers with osorer abruement.

Because of the greater dotall poselble, the profille method probebly elves a truer plecture of what occurred. The proflle method anems to offur advantagas in quentitat lvo ocoring and ladividual and group diagnosus. Hownver, te in unknown how much more dacalled scooring could be achleved if inore tape actpe ware adlled to the tank. Thre offact on acirer reliability of 
capes to observe and count is also unclear. On the other hand, scoring is simpler with the tapes. If the profile method is used the segment overlay should not be applied until after the scoresheet is filled out, to avoid influencing where the scorer marks the exposure. If a choice had to be made based on available data and usability of results, the indication currently would be to favor the profile method.

This test is highly terrain-dependent. During testing the position for the defilade was just large enough to conceal the tank and allowed little tolerance in height or width for a slightly incorrect position. On the other hand a much larger terrain feature would not provide much discriminacion. Perhap because of the size of the defilade or perhaps because of the indecision on the part of many drivers, the ground observers had trouble determining exactly at what point the driver was "in position." This was compounded by the fact that the defilade position was parallel with the path the tank had been following and movement towards the defilade was not always obvious from the ground acorer's location. Radio contact with the TC would have been helpful.

Minor material problems were encountered with the adhesive marking tape. Parts of several segments were corn off and segments located low on the tank became obscured with mud. A replacement tape with a better adhesive backing (such as duct tape or standard Army green tape but with high visibility) is needed.

One initial concern did not materialize. It was anticipated that later drivers could simply follow the tracks of previous drivers into the correct defilade position. Perhaps hecause drivers were so diverse in their reactiona, this did not occur. The problem could arise with more experienced drivers.

React To TC Command (Hull Defilade). In almost all aspects of test administration and execution, this test is like the test of the Missile, Duck command. The prime difference is in the desired outcome. In Missile, Duck the goal is to have the entire vehicle defiladed, while in Hull Defilade the turret must be exposed to engage the target. 
During the test che general target area was identified for the driver, but no clearly discernible actual target was used; additionally, the gunner's seat was not occupied. TC and scorers were, however, instructed to rate whether there was mask clearance from the gun to the target. They rated 13 drivers ( 41 percent) as having obtained mask clearance, 9 ( 28 percent) as not having obtained mask clearance and 10 drivers ( 31 percent) having missing data on this measure because TC failed to make an entry. While it is recommended that this measure be retained in future testing, the addition of a gunner would add to more complete and more accurate scoring.

Another measure that was recorded by the TC was the number of adjustments the driver made from his initial stopping position to a final position. The results, as shown in Table 22, reveal that mot drivers (18) made no adjustments in any direction. This measure was used because of the accepted technique of pulling into a facing hull defilade until the target is visible to the driver, then backing down to the point where the target disappears from sight.

Table 22

Number of Soldiers By Number of Tank Position Adjustments in Each Direction and Overall on Hull Defilade Test

\begin{tabular}{|c|c|c|c|c|c|}
\hline \multirow{2}{*}{$\begin{array}{c}\text { Number of } \\
\text { Ad justments } \\
\end{array}$} & \multicolumn{5}{|c|}{ Direction of Ad justment } \\
\hline & Forward & Back & Left & Right & Overall \\
\hline None & 22 & 22 & 19 & 21 & 18 \\
\hline One & 1 & 2 & 5 & 2 & 4 \\
\hline Two & 1 & 0 & 0 & 1 & 0 \\
\hline Four & 0 & 0 & 0 & 0 & 1 \\
\hline $\operatorname{six}$ & 0 & 0 & 0 & 0 & 1 \\
\hline
\end{tabular}

It is not surprising that this technique was not widely used by novice OSUT-level drivers who may either be unaware of it or insufficiently experienced in its execution. However, even with experienced drivers who might use subsequent position adjustments, the measure is of dubious value because 
of the confusion that can result in its use. While some Forward-Back Movement is a "positive" result--indicating use of a desirable technique--at some point the number of adjustments takes on a negative value because it indicates poor position selection, poor movement, or poor vehicle control. Because of the potential confusion atcendant on this measure it is recommended it be dropped from future applications.

Time was recorded from isouance of the Hull Defilade comand until the driver obtained his final position. TC/scorers also evaluated whether the speed was Appropriate or Too Slow. The speed for 72 percent of the drivers was rated as Appropriate and for 28 percent of the drivers was rated as Too Slow (three drivers' speed ratings were missing). However, unlike the results obtained in a similar measure for Missile, Duck, the results here did not intercorrelate (Table 23), partially because of the small number of ratings in the Too slow category. Before deciding to drop this rating, additional data are needed. However, if almost three-fourths of OSUT drivers are rated in the Appropriate category, a more even division is not expected with more experienced drivers.

Table 23

Actual Test Times of Soldiers by Levels of Speed Rating on Hull Defilade Test

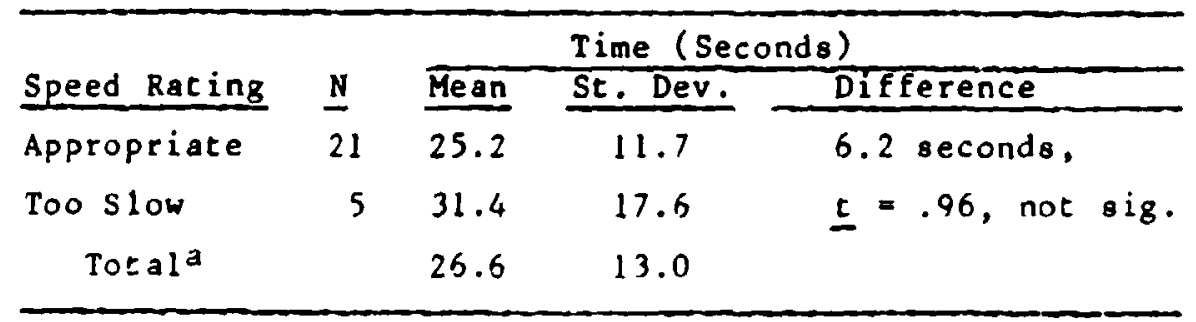

$a_{\mathrm{N}}=29$.

A subjective measure of stopping (Smooth, Jerky, Abrupt) was also scored by the TC/scorers. They rated the majority of soldiers (19, or 61 percent) as having a smooth stop; only 2 ( 6 percent) had abrupt stops. Because of the lack of a clear use for this measure it is recommended that it be dropped. 
As with the Missile, Duck test, the ground observers made two separate measures of tank exposure, one using strips of tape applied to the tank and the other using the tank profile. Both methods are described in the Missile, Duck test. However, both methods were somewhat more complex in application and analysis for this test. Whereas the Missile, Duck view from the ground was always of only one side of the tank, the hull defilade presentation was a head-on view that included portions of both right and left sides as well as the front of the vehicle. For the Missile, Duck test total defilade was the goal, while Hull Defilade requirements for a "good" score demand that the hull be concealed while the turret is at least partially exposed to allow engagement. A further complexity of this test, as administered, is scoring of the position of the turret. The driver cannot be held accountable for the orientation of the turret which, to some extent, determines which portions of the turret are visible to a ground observer; this is a gunner responsibility. Without gunners there was no way to standardize this aspect. Future testing should require a gunner who is instructed to lay on the same point each time, assuming he had mask clearance.

of the 27 soldiers for whom scores were complete, scorers were in full agreement on number of turret, hull front, and hull side tapes in 19 (70.4 percent) cases. As shown in Table 24, scorer agreement was best on scoring the turret but lower for the hull front and hull sides separately. When the huli front and side tapes are considered as a whole, agreement drops to 78 percent. Since more variations are possible with both front and sides of the hull, this is reasonable. On the hull, most agreements came when none of the tapes was exposed, and with the turtet most agreements occurred when all of the tapes were exposed, a result consistent with the frequency of these occurrences. Most of the scorings fall in the all ( 3 tapes) or nothing ( 0 tapes) areas with very few interim ratings or partial exposures.

Table 25 shows scorer agreement using the profile marking method. Agreement is by profile segments, computed for the right side profile, the left side profile, and for both profiles combined. With one exception (segment 6) the left side profile agreement is adequate, while the tight side profile is deficient in fnur segments: 1, 2, 4, and 6 . The main area of scorer disagreement is in profile segment 6 , which is the rear half of the 
Table 24

Number of Soliders With Scorer Agreements on Patterns of

Tapes Visible on Hull Defilade Test

\begin{tabular}{|c|c|}
\hline Measures & $\begin{array}{l}\text { Number of } \\
\text { Agreements }\end{array}$ \\
\hline $\begin{array}{l}\text { Tapes Visible, Hull Front, Hull Side, and Turret } \\
\text { No Tapes Visible } \\
\text { No Hull Tapes, Three Turret Tapes } \\
\text { No Hull Front, One Hull Side, Three Turret Tapes } \\
\text { One Hull Front, No Hull Side, Three Turret Tapes } \\
\text { Two Hull Front, No Hull Side, Three Turret Tapes } \\
\text { Full Agreement Percent }(N=27)\end{array}$ & $\begin{array}{c}1 \\
12 \\
1 \\
3 \\
2 \\
70.4 \%\end{array}$ \\
\hline $\begin{array}{l}\text { Tapes Visible, Hull Front and Hull Side } \\
\text { No Tapes Visible } \\
\text { No Front, One Side Tape } \\
\text { One Front, No Side Tapes } \\
\text { Two Front, No Side Tapes } \\
\text { Full Agreement Percent }(N=27)\end{array}$ & $\begin{array}{c}15 \\
1 \\
3 \\
2 \\
77^{2} .8 \%\end{array}$ \\
\hline $\begin{array}{l}\text { Tapes Visible, Hull Front } \\
\text { No Tapes Visible } \\
\text { One Tape Visible } \\
\text { Two Tapes Visible } \\
\text { Full Agreement Percent }(N=30)\end{array}$ & $\begin{array}{c}17 \\
5 \\
2 \\
80.0 \%\end{array}$ \\
\hline $\begin{array}{l}\text { Tapes Visible, Hull Side } \\
\text { No Tapes Visible } \\
\text { One Tape Visible } \\
\text { Full Agreement Percent }(\mathrm{N}=28)\end{array}$ & $\begin{array}{c}23 \\
1 \\
85.7 \%\end{array}$ \\
\hline $\begin{array}{l}\text { Tape Visible, Turret } \\
\text { No Tapes Visible } \\
\text { Three Tapes Visible } \\
\text { Full Agreement Percent }(\mathrm{N}=31)\end{array}$ & $\begin{array}{c}1 \\
27 \\
90.3 \%\end{array}$ \\
\hline
\end{tabular}


turret. While not entirely explainable this may well be an artifact of the profile overlay. The division between segment 4 and 6 is the apex of the turret glacis, with segment 6 including the bustle area. Many of the scorer markings were just over the line dividing segments 4 and 6 .

Table 26 shows the scorer agreement on individual evaluations for left and right profiles. Full agreement on all 7 segments is very low and increases considerably but not sufficiently when the controversial seguent 6 is excluded.

Another way of analyzing the results is shown in Table 27 . Since the critical distinction for scorers is whether the turret was exposed and the hull concealed, agreements on just those factors were computed without regard to the extent of the exposure or concealment. Only a slight increase in agreement is noted; that agreement does not differ from the agreement for a similar couputation using the tapes.

An even more lenient measure of agreement on the profile method is to count an agreement whenever both scorers recorded any portion of the turret and hull exposed, on the right or on the left (Table 27). Even this agreement is less than 80 percent. It should be noted, however, that with the tape method it appears that one tank was fully concealed, while the profile markings indicate that every tank was at least partially exposed.

The profiles were given to the scorers without training or without any detailed explanation on their use. The use of both the left and right profile was not a stated requirement, and while the scorers generally used both, the prime area of concentration appeared to be on the left profile, probably because in most cases more of the left side of the tank was presented to them. Some scorer training and more detailed protocols would increase scorer reliability significantly in this test, but the effort may not be warranted. The tape segments appear to provide adequate measures for this test, and increased scorer training and practice might also improve agreement there. The profile method could provide more points of quantitative measurement, but the interpretation of this measurement is somewhat 
Table 26

Number of Soldiers With Scorer Agreements on

Three Patterns of Tank Segments Exposed Using

Profile Overlay on Hull Defilade Test

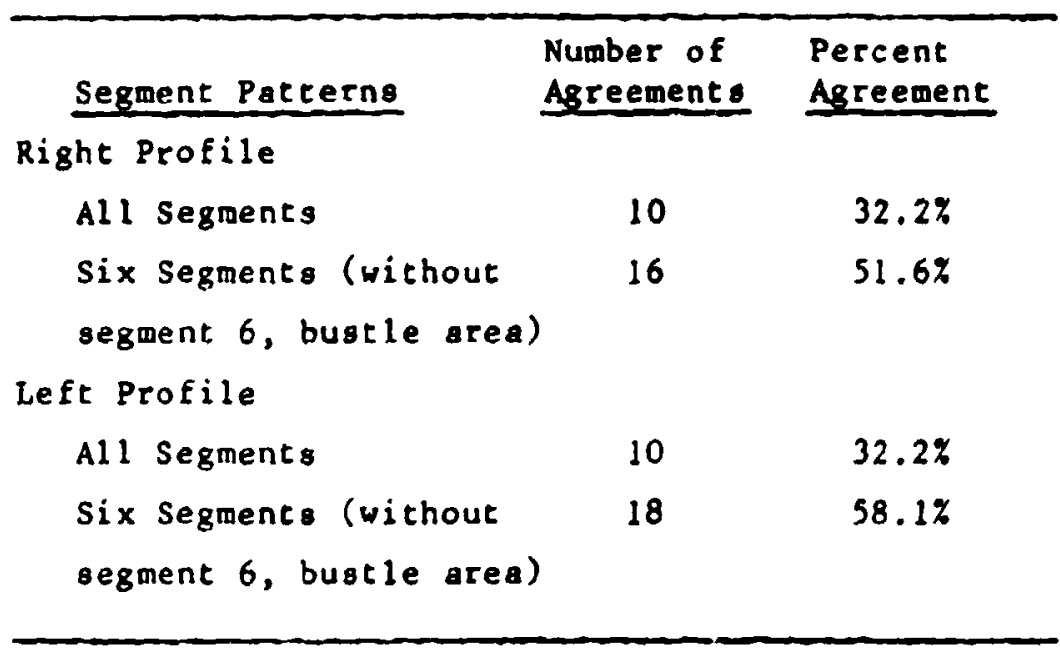

Table 27

Number of Soldiers With Scorer Agreements in Three Categories of Tank Exposure Using Tape Method and Profile Overlay Method of Determining Tank Exposure on Hull Defilade Test

\begin{tabular}{|c|c|c|c|c|}
\hline Outcome. & Tape Method 8 & $\frac{\text { Profile }}{\text { night }}$ & $\frac{\text { Overlay }}{\text { Left }}$ & $\frac{\text { Method }}{\text { Either }}$ \\
\hline Turret and Hull Cuncealed & 1 & 6 & 1 & 0 \\
\hline Turret Exposed, Hull Concealed & 13 & 12 & 16 & 16 \\
\hline Turret and Hull Exposed & 8 & 2 & 6 & 8 \\
\hline Total Agreement Percenta & $71.0 \%$ & $64.5 \%$ & $74.2 \%$ & $77.4 \%$ \\
\hline
\end{tabular}

$a_{N}=31$. 
complex. Unlike the Missile, Duck test, Hull Defilade requites some exposure of the turret. Scoring complexity is compounded if the present twoprofile diagram is retained. The continued use of this method is not recomended for this test; however, it is recommended that the utility of the method or some variation be further explored.

Problems with tape durability and visibility similar to those experienced on the Misaile. Duck test occurred with this test. The hull defilade position was adequate for the requirement but two cautions are necessary for future test applications. Firet, only one edequate hull defilade position can be locaced in the immediate arsa if accurate off-tank scoring is to be achieved. Second, foliage at the hull defilade position wust be minimal. In coring, foliage concealing the hull is not dittinguished from hull cover. poliage concealing the turret can also result in acoring the turret as covered (i.e., en inadequate position) while from the tank position the field of fire is inadequate.

Somewhat unexpectedly, OSUT soldiers appeared to have fewer problems with the concept of Hull Defilade than they did with the concept of Miselle, Duck. And as with the Miselle, Duck test, enough variation was observed in performance to conclude that tracking previous performers into the hull defilade position was not widespread. Again, with more experienced drivers this latter occurrence cannot be ruled out.

One further requitement to oimplify the teat administration process is the need for an enemy tank silhovette target for the driver to identify. While realiem dictates that the driver will not always see the target, the test requirement that no detalled guidance be given the driver in the hull defilade postition requires that come vioual cue be offered.

\section{Tect Intercorrelatione}

A finel set of analyeen concerned the extent to which the tests and the variables within testn cended to measure independent driving abilities. Each varlable was scored according to the recommendations in the previous sectiona. Among the 4 tests adminintered on the firat occasion, 19 measurea were retained; among the 5 cacts administered on the second occasion, 17 
measures were retained (see Table 28). Intercorrelations were then computed among all variables in each set. Kendall correlations were used because so many of the variables ( 14 in the first set, 11 in the second) had severely restricted ranges of possible values. Because the null hypotheses postulated that relationships do exist, and the research hypotheses were that the behaviors are independent, the protection (aignificance) levels of the correlations begin at .10 . On variables scored by two observers, cases were included in the computations only when the observers' scores agreed. The two correlation matrices are presented in Tables 29 and 30 .

In the first set of correlations, 45 of the 111 ( 26.3 percent) coefficients were statistically ignificant. However, 8 of the 45 are correlated because of algebraic interdependence: On the test Follow Ground Guide Signals, strikes before, during, and after the turn are components of total strikes and are, of course, correlated with total strikes; likewise on Right and Left Turns, strikes before, during and afterl are correlated with total right and left turn performances. Overall, there are 13 variables that are scored either as no strike/strike or as no strike/one strike/two or more strikes, yielding 70 algebraically independent correlations; of these, only 5 ( 7.1 percent) are totistically significant. Thus the various measures of driving ability in terms of barrier strikes, counted during the Follow Ground Guide Signals and Right and Left Turns tests, appear to be modestly relaced at begt. No consistent patterns emerged to suggest dropping any of the measures as redundant. Barrier strikes counted on the Align Tank for Width test were not correlated with any of the other measures of strikes.

The three measures of time froin the follow Ground Guide Signals and Right and Left Turns tests were all intercorrelated, indicating that soldiers tended to be consistent in their driving speed across tests. On the Follow Ground Guide Signals test, time was related to barrier strikes after the turn, and for both the left turn and the right turn the time and overal of the otrike measures were significantly correlated, with soldiers who struck the barrier requiring more time to perform. Thus time probably does not reflect careful driving throughout the turn, but may reflect careEul driving in reaction to barrier strikes having occurred.

lRight turn only; no strikes were recorded after the turn on the left turn. 
The two measures of length of the turn from the Right and Left Turns test were correlated with each other, and correlated negatively with the time measures. Additionally, strikes during the right turn were correlated with both length measures, Overall, the three-way pattern is that soldiers with barrier strikes took more time but had shorter turn radius than did soldiers with no barrier strikes.

The pattern is reversed when barrier strikes on the Align Tank for Width test are analyzed with the Right and Left Turns time and length weasures. Significant correlations indicate that soldiers with barrier strikes on Align Tank for width required less time and had longer turn radii on Right and Left Turns than did soldiers with no barrier strikes. Clearly the observations of barrier strikes on Align Tank for Width and on Right and Left Turns are indications of different dimensions of driving ability.

The number of correct decisions on the Width Judgment test was not consistently related to any other measures. Of the 13 such measures obtained, significant correlations occurred with two measures of barrier strikes. Both correlations were such that more correct decisions were associated with more strikes. Correct decisions were also significantly correlated with the length of the right turn, the shorter lengths being associated with more correct decisions. In general, it appears that the perceptual-cognitive skill involved in the width judgments is independent of the perceptual-motor skill involved in the other obstacle/Judgment tests.

Of the 120 correlations in the second set of analyses, 44 ( 36.7 percent) were statistically significant. Unlike the Width Judgment test analyzed with the first set of tests, the number of correct decisions on the Height Judgment test was significantly correlated with 5 of the tactical driving measures: number of transmission shifts on the Control Tank During Main Gun Engagement (but note that $N=4$ ), time and the TC evaluations of speed and timing on the Missile, Duck test, and concealment measured by the profile method on the Missile, Duck test. In all cases, more corrct decisions are associated with the desirable ("correct") rating (fewer shifts, less $t$ ime, speed fast enough, timing immediate, fully concealed). 
On the test Control Tank During Main Gun Engagement, time and number of transmission shifts were positively correlated, based on the eight soldiers for whon shift counts were obtained. Time was also correlated with time measures on the Acceleration and Stopping test and the Hull Defilade test, and with the timing rating, but not actual time, on the Missile, Duck test. The number of shifts was correlated with the three movement measures on the Missile, Duck test (speed, timing, and time) for the eight soldiers scored. Thus the Control Tank test skills assessed here may be redundant with the movement skills of the Missi.e, Duck test, although further data collection is required to ensure the replicability of these findings.

Within the Acceleration and Stopping test, time and distance from the finish line were positively correlated, as were distance and the stopping evaluation--a smooth stop associated with finishing close to the line-although time and the stopping evaluation were not related. The interpretation is that the soldiers who stop smoothly also stop ciose to the line, and the soldiers who finish closest to the line also finish most quickly. But because the correlations are not perfect the smooth stop is not an indicator of fast or slow performance. The three measures have scatered correlations with measures of the Missile, Duck test: time with the timing rating and one method of rating concealment, distance with the speed rating, and the stopping evaluation with the tape method of rating concealment. In addition, the time for the Acceleration and Stopping test was positively correlated (i.e., in the desirable direction) with all ratings in the Hull Defilade test, while the measure of distance from the finish line was correlated with two of the methods of rating hull concealment. Further data collection should be initiated to determine whether or not the Acceleration and stopping test measures driving abilities that are indepencient of those measured during the Missile, Duck and Hull Defilade testo.

The Missile, Duck test appears to consist of two kinds of measured skills: movement and concealment. The speed, timing, and time measures were significantly intercorrelated, and the tape method and profile method of assessing concealment were intercorrelated. Timing was also related to orie of the concealment $r a t i n g s$ (immediate reaction and more complete 
concealment), which is a slight indication that the two areas may have some common underlying ability; this may be little more than understanding the concept of the rask.

On the Hull Defilade cest, the three measures of concealment--tape method, profile method, and TC evaluation of mask clearance-were likewise intercortelated, but speed and time were not. Time was correlated with two of the concealment measures, with soldiers requiring less time to achieve a correct pasition (hull concesled, turret exposed). The TC ratings of speed and mask clearance were also correlated. In contrast to the Missile, Duck test, it appears that the movement and concealment abilities are more strongly interdependent in the Hull Defilade test.

Intercorrelations between the two tests are inconsistent. Of the $s i x$ correlations amoung measures of concealment, only two were significant despite strong within-test correlations. Time on Hull Defilade was correlated with both timing and time on Missile, Duck, but the two ratings of speed were not correlatd. Strangely, soldiers who required less time on Misaile, Duck were rated as too slow on Hull Defilade.

In sumary, the two sets of intercorrelations indicate that the Obstacle/Judgment cests are probably independent. Although the four tests are undoubtedly measuring some common dimensions of driving ability, the tests are sufficiently different to warrant continued use of all four. Whether or not the fifth test, Height Judgment, is related to the four tested earlier cannot be determined. Among the Tactical Driving tests, there is some evidence that the skill measures on the tests of Control Tank During Main Gun Engagement and Acceleration and Stopping are not assessing unique skills, but have much in conmon with the movement ratings on the Missile, Duck and Hull Defilade tests. Neither set of measures may be substituted for the other, however, and more success in obtaining data on the Control Tank test may reveal that the tests are as different ss their titles suggest. 
$\therefore$

$\because$

$r$

THIS PACE INCENTIONALLY LEPT BLANK. 
The measurement of nonprocedural driving skills is ade more difficult by a lack of clear deolgnation of the scope of driver tauks. The approach caken in this resestch has been to define driver taske in somewhat arbitrary

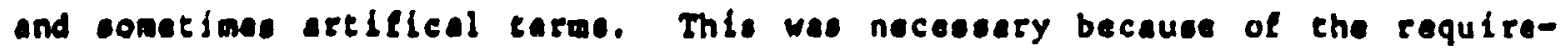
ment to tsolate certain behaviors for mesurament. While the selection of these behaviors was based on a certain amount of enalyois and attention to whet can reasonably be expected of drivers in the field, the end products are rertainly neither inclusive of all desired behalvors nor are they probably univeraelly acceptable es the definition of the driver job. Therefore eovaral cautions are needed:

- The casts and taet cleles should not be construed as a redufinteion or new asilgnment of driver teaks. Behavlore heve bann eroupad undar elmilar funceiunal areas and in eome caces (i.e., Mlestle, Duck: Hull Defliede, Matn Gun Ingagement) thay are cested in a partial cectical context. Although a broader definintion of the drivur'. Job (beyond the orncadural tasks) way be a requitoment, that was not the goal of this research oflore.

Crew Interact!on wes not a cousideration lo the testing. The extetence of and necessley for TS, gunnur and oven londer Interaction with the driver is fully rocosnized. But tha extient of that Intoraction raquires a complex toan task enelyoils bayond the acope of chis work. For purposen of uveluation tt was neceusary to leolate the driver'o behavior by exciuding any TC or other lnceracton Juring the tane even cisesgh this might make tha teatad hehavior inconaintent with job requireinenea. Is to the inconetacency of ineeraction from craw to crow and the Inabllity to be definitiva about the extont of interascion that made this tecesasy. Although the crleictam that the coate requite more ehan to requlred of drivers on tha job lo not lightly diamianed, it to neverthelene melntalnad that drivere who are capable of parforming with minimal interaction are pretentinlly buttar drivers, rngardlass of the latitude or diruction thay ore actually wiven during on-che-job pertormanca.

(1)

Whiln the cases wara to bo dovelopad an criterlon ceetu, the affort ts date has not eatalbliehand criterion standerela. The limitad ample teated cona inted of osur perconnel only. While le may be denirable to cotabliah performance ncandarda tor this luval of driver, no inta

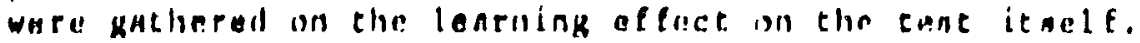


One caution that will affect standards establishment is the effect of the test conditions (terrain, weather, surface conditions, vehicle conditions) wherever the test is applied in the future. These variables may ultimately prove to be an insurmountable obstacle to eatablishing an absolute standard for some measures.

Although the purpose of this research was not to develop operational tests for general field application, the benefits of using these tests in that capacity should not be ignored. The primary benefit is that the tests focus on nouprocedural aspects of the driver's job and this is a neglected area in current field driver evaluation situations. Additionally, che tests are fairly inexpensive to administer and are easy to score. The main caution is that in field units, they should be used primarily in a training mode. Currently they are not intended as GO-NO 60 scored tests because of the absence of evaluative standards discussed earlier. Only normative scores may be obtained as the tests are now configured. These may be applied to compare drivers within a unit (platoon or company) or to measure the same driver's performance over time in repeat applications of the test.

The major effort of this research has been to focus primarily on the development of reliable performance measures as a necessary initial step in establishing measurement criteria. Assessment of reliability is the most crucial aspect of instrument develupment. Without reliability there can be no test validity and all instrument refinement, test and administration, scorer training and conditions specifications must concentrate on increasing reliability. Unless scoring reliability has been established, any further application of the instruments is a needless waste of resources. Based, however, on the initial results and recommended modifications there is ample evidence that these tests hold promise as reliable quantitative instruments for measuring performance and producing criteria to use in yardstick comparisons with simulator-measured skills. While more replications and developmental refinements of the test are needed before measurement can be applied against a simulator, the tegts contained in Appendix $A$ and as modified in the Results section should provide the basis for that refinement. 
It must be recognized that while the tests as constructed appear to give good representative coverage of many nonprocedural driving skills, this research effort has not attempted to analyze all nonprocedural driving tasks to insure comprehensive coverage. It is likely that if comprehensive measurement of driver skills is to be obtained, more tests or scored events will have to be added to the sest package. Two cautions are necessary if such effort is to be undertaken. First is the requirement to obtain empirical data to sscertain whether or not measures are redundant across tests. Second is to remain within feasibility constraints for administration. Already the existing package of tests strain the abilities of a unit to support. For example, to administer the existing tests to more experienced drivers--assuming the desired number of drivers was approximately 30--would require the commitment of an operational tank battalion for a minimum of two days.

Effort must continue on the reliability issue, both to ensure that reliability remains high on the measures selected and to increase reliability on other desired measures. Obviously one method, discussed earlier, is to ensure that future replications allow time, equipment and personnel availability to permit comprehensive scorer training concentrating on the areas of difficulty specified in the Results section of this report. How ever, the most promising path to increased reliability is to look for ways to replace human judgment. Early in this effort, automated scoring was considered and although availability of operational tanks and adequate test personnel precluded tryout, enough preliminary information was gathered to indicate promise in this area. Such automated scoring devices as photo electric cells, engine monitors, TV recorders and hand-held data recorders could supplement or in some cases replace scorer judgment on selected measures. This ares is important to consider, particularly in those tests where many measures occur in an extremely short period of time such as in many of the Tactical tests.

As confidence is being established in the reliability of the tests, future efforts must also address the validity issue. Normally, in performance cests the validity issue depends on how closely by the test situation approximates the "real life" situation. As has been discussed, the tests 



\section{RECOMMENDATIONS}

This research has established a methodology for test developrent to serve as the basis for identifying and measuring driver skills. It has established a core of reliable test instruments to measure specific and supporting driving skills and to serve as measure of simulator skills. But further efforts in this area are warranted; specifically further research is recommended to accomplish the following:

- Resolve validity questions by exploring other aspects of tank driving skill measurement and evaluation.

- Administer the existing tests to more experienced drivers to obtain performance data on other than a novice group.

- Continue to explore the domain of "driving skill," adding or modifying tests as needed to increase coverage.

- Explore the possibilities of automated scoring to replace or supplement judgmental scoring. 
Baker, R. A., \& Roach, E. F. (1960). The Armor Mastery Test Battery. Fort Knox, KY: U. S. Army Armor Research Urit.

Burroughs, S. L. (1981). Criticality of Nonprocedural MI Driving Subtasks. Unpublished manuscript.

Eaton, N. K., Bessemer, D. W., Kristiansen, D. M. (1979). Tank Crew Position Assignment (ARI Technical Report 391). Alexandria, VA: U. S. Army Research Insticute for the Behavioral and Social Sciences. (AD AO77 841)

Greenstein, R. B., \& Hughes, R. G. (1977). The Development of Discriminators for fredicting Success in Armor Crew Positions (Research Merrorandum 77-27). Alexandria, VA: U. S. Army Research Institute for the Behavioral and Social Sciences. (AD AO77 944)

O'Brien, R. E., Harris, J. H., Osborn, W. C., Healy R. D. (1979). Tank Crewman (M6OAl) Readiness Tests (ARI Kesearch Products 79-13, 79-?4, 79-15). Alexandria, VA: U. S. Army Research Institute.

U. S. Army. (1975). Interservice Procedures for Instructional systems Development (TRADOC Pam 350-30). Fort Monroe, VA: Training and Doctrine Commarid. 


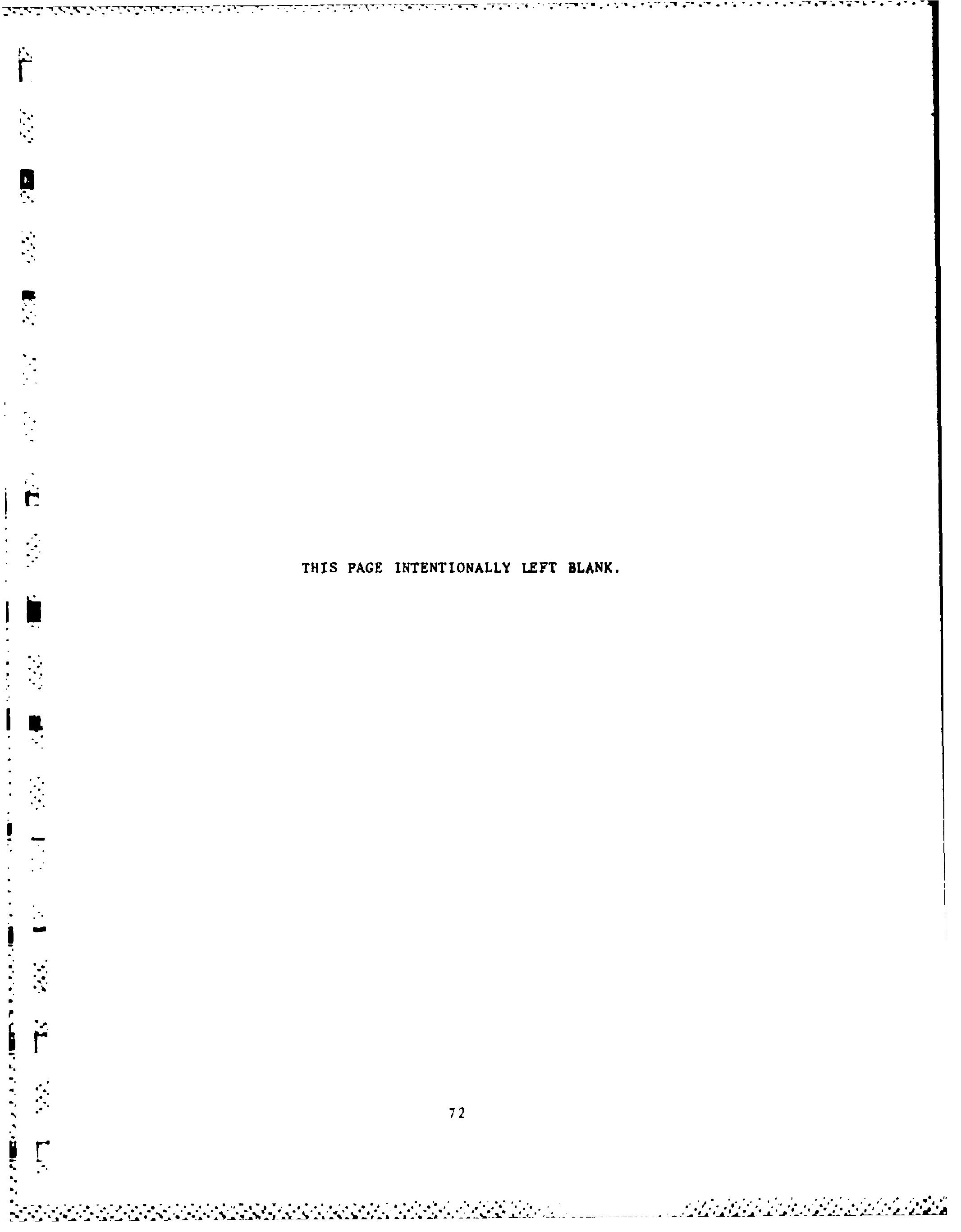




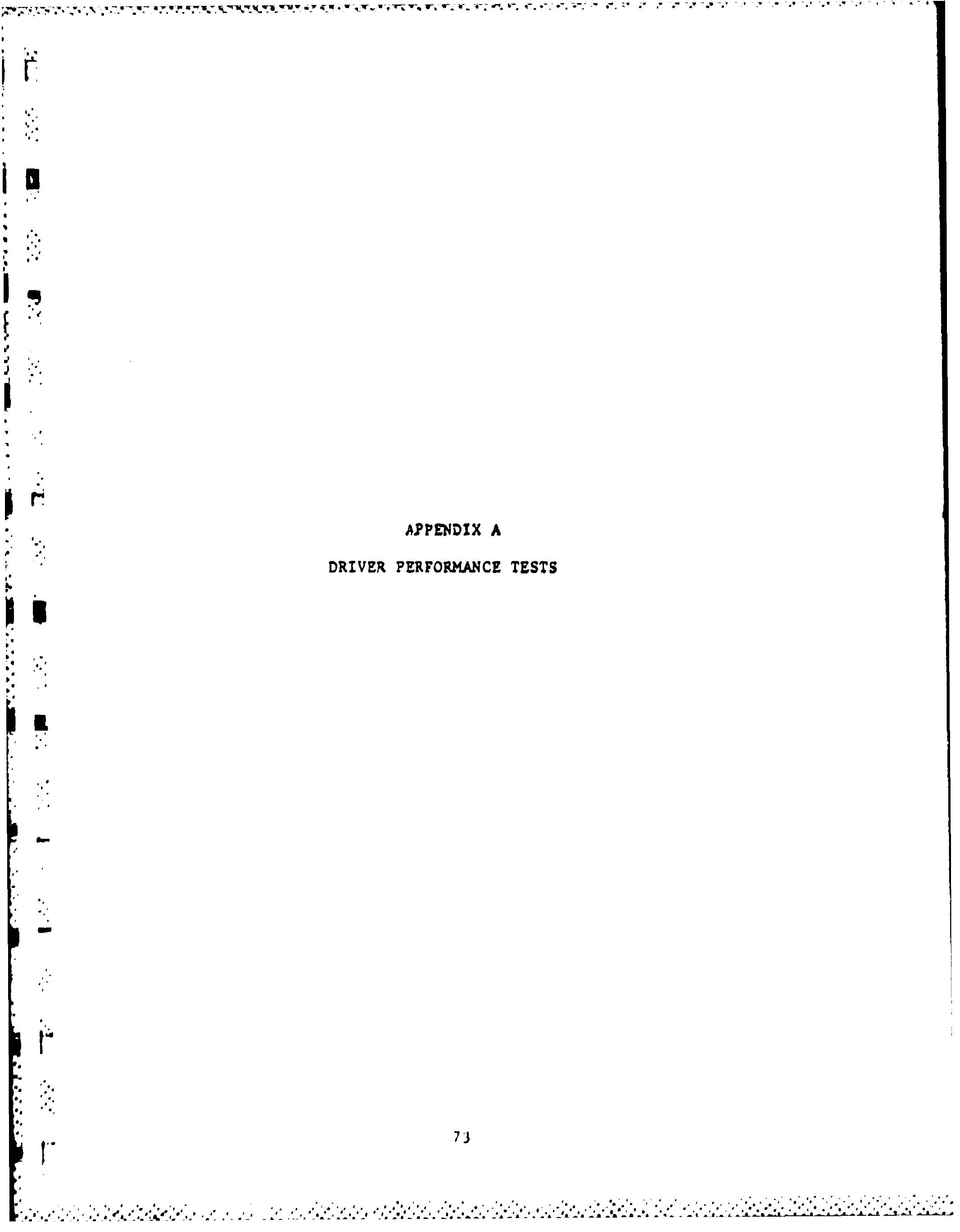


TEST CONDITIONS: Conducted on hard surface with one side marked with engineer tape. (NOTE: The same site that is used for Right and Left Turns may be used.) Pylons or stakes should be set up a distance of $18^{\prime}$ out from the turn and the entrance and exit width set at $13^{\prime}$.

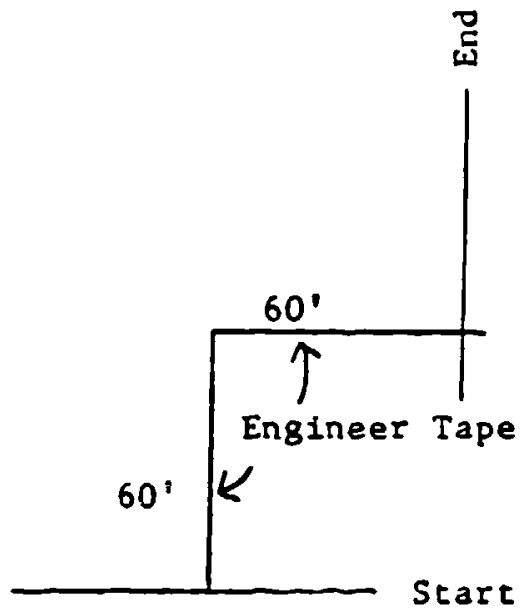

EQUIPMENT/PERSONNEL REQUIRED :

Equipment :

$$
\begin{aligned}
& 1-\text { M tank } \\
& 130^{\prime} \text { englneer tape } \\
& 6-51 \text { stakes or pylons } \\
& 4-2 \text { stakes } \\
& 1 \text { - stopwatch } \\
& 50 \text { measuring tape }
\end{aligned}
$$

Personnel:

$1 \mathrm{TC}$

1 Scorer

2 Ground Guides

\section{TEST PREPARATION :}

1. Erect the engineer tape along the inside (right hand) of the lane.

2. Place pylons or stakes at a distance of $13^{\prime}$ at the entrance and exit points and $18^{\prime}$ out from the $90^{\circ}$ turn.

TEST ADMINISTRATION (TC):

1. Back the tank up to the starting point and positioned within one foot of the engineer tape.

2. Read the instructions to the driver before mounting the tank.

3. Do not give any assistance or guidance to the driver during the cest. No scoring is required from the TC: 
TEST ADMINISTRATION (GROUND GUIDES):

1. One ground guide is positioned in the rear of the tank; the other provides the signals to the driver.

2. The first signal given will be to start the tank.

3. Give ground guide signals as necessary to get the tank through the course keeping the rank as close a!s possible (within two inches except at the turn) without striking the tape.

4. If you give an incorrect signal causing the tank to touch any of the barriers, notify the scorer.

TEST ADMINISTRATION AND SCORING (GROUND OBSERVER):

1. Start timing when the ground guide gives the first signal. Stop timing when the front of the tank clears the end point.

2. Record each time any part of the tank touches the engineer tape, stakes or pylons.

3. If there was a barrier strike caused by an incorrect ground guide signal do not count this as a barrier strike. 
INSTRLCTIONS IO DRIVER: During this test you will drive the tank following a ground guide. You will be required to back the tank as, the ground guide directs. Leave your hatch open. Are there any questions? 
FOLLOW GROLND GUIDE SIGNALS

Examinee Name:

Trial Number:

$\longrightarrow$
Date \& Time:

IC :

Scorer :

MEASURES :

1. Number of barrler strikes:

Before turn

During turn

After tum

2. Time:

COMRENTS :

$r$ 
IEST CONDITIONS: A hardstand allowing a right/left angle is required. An approach and exit "lane" each approximately 20 meters long is required and a turnaround area after the end point is required, 1.e., (Note: The same site that 1s used for Pollow Ground Gulde S1gnal. can be used.)
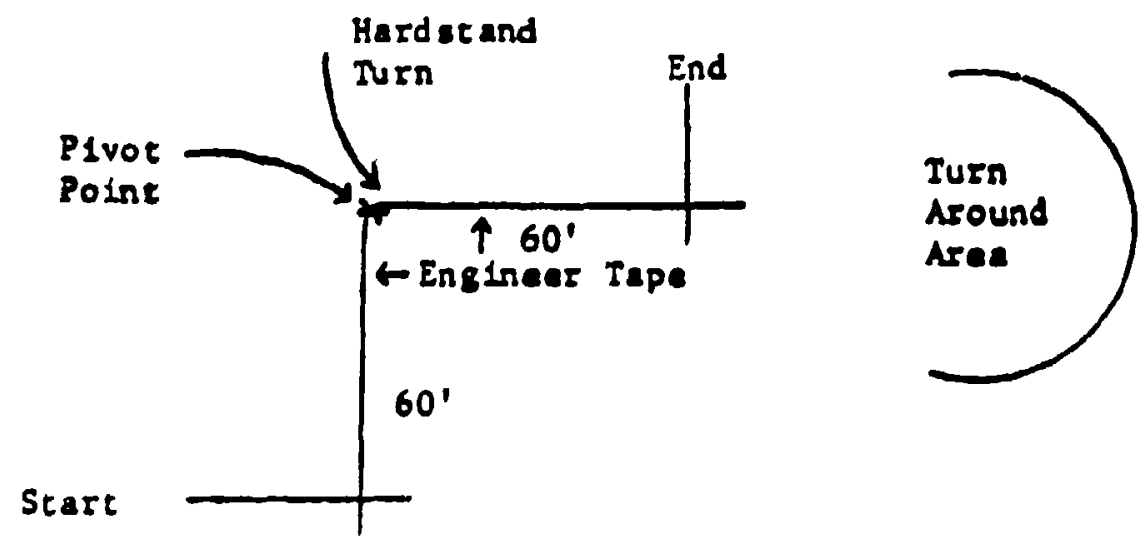

EQUTPMENT/PERSONNEL REQUIRED:

Equ1pment:

1 - M1 tank

$130^{\prime}$ engineer tape

6 - S' stakes or pylone

$4-2^{\prime}$ stakes

50' measuring tape

1 - stopwatch

1 - broow

\section{Personnel:}

1 TC

2 Scorers

\section{IEST PREPARATION:}

1. Erect the engineer tape on stakes or pylons on the inolde of the turn at or slightly below fander halght. The tape wust make a $90^{\circ}$ angle at the pivor point.

2. Mark the start and and points with stakes and engineer tape.

3. Spread a light covering of dirt over the hardstand at the turn co aselst in ocoring the radius of the turn.

\section{TEST ADMINISTRATION (TC):}

1. Position the tank, entine of , at the utart point.

2. Read the Instruct lons to tha driver bafore mounting the tank.

3. hloen the driver has ritartied the tank, conunand DRIVFR, MUVE IUT and Hernill thas beurer. 
4. If neressary, assist or direct the deiver in curning around after he has pased the end point.

5. Direct the driver to stop at the "end" polnt after the turn around.

6. Command DRIVER, MOVE OUT and agnal the scorer.

7. If the driver aske 18 he should pivot curn tell him he may.

8. Do not sesise the driver in making the turn. No scoring is required frow the TC.

TEST NDMINISTRATION AND SCORINC (GROUND OBSERVERS):

1. Postelon one scorer on the Inside (engineer tape alde) of the lane and the othet on the outside.

2. One ecorer muet keep track of eloe. Start the tire when the IC agmels and etop the tire when the rear of the tank clears the and poine.

3. The Inolde scorer will observe and record any tine the tank teuches the ensineer tape or stakes.

4. The outelde scorar will wark the widest poinr. reached by the rear of the track on the turn.

9. Meseure the discance frow file plvot polnt to the widest point resched on the turn.

6. Sweep dirt over the turn to assist in scoring the loft turn.

7. Ropast the ucosing procese for the laft turn. 
INSTRUCTIONS TO THE DRIVER: During this test you must drive this lane staying as close as possible to the engineer tape without hitting the tape. After you complete the first run we will turn the tank around and you must complete the course again from the opposite direction. I will not be able to assist you during the course. You will drive with your hatch open. Do you have any questions? 
Examinso Vame:

Trial Number:

MEASURES :

RICHT TURN

Radius of right turn:

Did tank touch engineer tape: YES NO

If YES was 1t: Before Turn
Date \& Time:

TC:

Scorer (s):

Time:

\section{LEFT TURN}

Radius of left turn:

Did tank touch engineer tape: YES No

If YES was 1t: Before Turn During Turn After Turn IIme:

CORMIENTS : 
TEST CONDITIONS: Test is conducted in open terrain with three sets of pylons or portable stake $=$ set up at approximately $50^{\prime}$ intervals and offset. There must be sufficient room to bypass each set of width markers. Markers must be movable so that adjustments can be made between tests. Markers will be set up at widths of 157", 169", and $144^{\prime \prime}$.

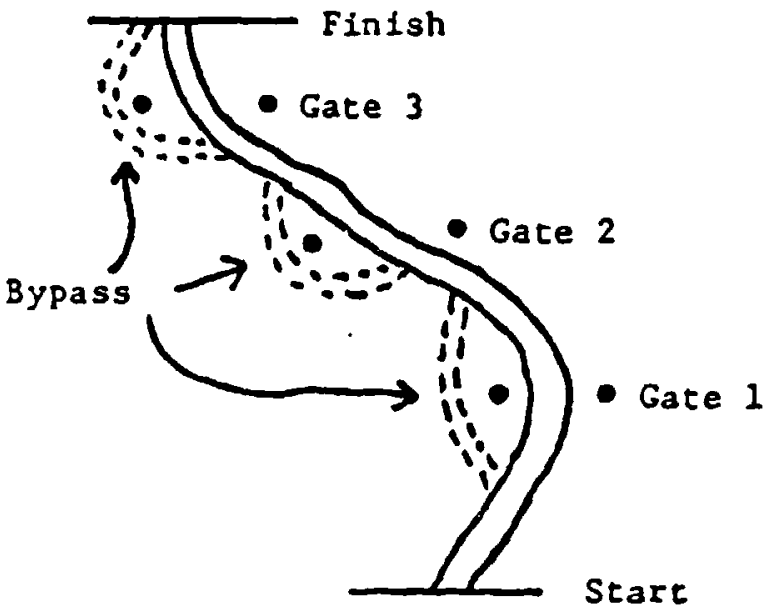

EQUIPMENT/PERSONNEL REQUIRED:

Equipoent:

$$
\begin{aligned}
& 1-\text { Ml tank } \\
& 20^{\prime} \text { engineer tape } \\
& 4-2 \text { stakes } \\
& 6-5 \text { stakes or pylons } \\
& \text { 50' measuring tape } \\
& 1 \text { - stopwatch }
\end{aligned}
$$

Personnel:

1 TC

1 Scorer

\section{TEST PREPARATION:}

1. Set up the three sets of gates at widths of 157", 169" and 144". Set up the gates so that all three are not in a stralght ilne.

2. Mark a start and finlsh point with the short stakes.

3. Drive each bypass area at least once to mark $1 t$.

4. Vary the width of each gate after each run using the same three widths but moving the location, 1.e., If Gate 1 was 144" for the ftrst run te should be adjusted to $169^{\prime \prime}$ for the second examinee and so on. 
TEST ADMINISTRATION (TC):

1. Position the tank, engine off, at the rart point.

2. Read the Instructions to the driver before mounting the tank.

3. When the driver has started the tank command DRIVER, MOVE OUT and signal the scorer.

4. Do not assist the driver in deciding whether to pass thruugh the gates or during the passage. No TC scoring is required.

5. If the driver pulis up to a gate and then decides he wants to bypass, you may assist hill in backing up.

\section{TEST ADMINISTRATION AND SCORING (GROUND OBSERVER):}

1. Mark the width of each of the gates on the scoresheet.

2. Position yourself where you can observe all three gates and the finish point.

3. Start the time when the TC signals and stop the time when the rear of the tank passes the finish point.

4. Record for each gate whether the driver passed through or bypassed. Circle for each gate whether the tank cleared the gate. If any part of the tank touches the stake or pylons, circle No. If the gate was bypassed circle NA.

5. Adjust the width of at least two of the gates after each run. One of the two must be the narrowest gate (144"). The width of the gates must be exact for each run. Use an assistant or the IC to help adjust the width. 
INSTRUCTIONS TO THE DRIVER: During this test you must judge whether you can pass through three openings. If you think you can pass, drive you think it is too narrow, you must drithout hitting them. If left). I cannot help you in making the dive around to the (right or the markers. You will drive open the decision or driving between open hatch. Do you have any questions? 
Examinee Name:

Trial Number:

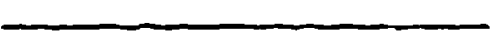

$\because$

T1me:

COMENTS :
Width:

1. Passed through Bypassed

2. Cleared Gates: YES NO

NA

GATE 2

Width:

1. Passed through

Bypassed

2. Cleared Gates: YES

NO

NA

GATE 3

Width:

1. Passed through

Bypassed

2. Cleared Gates: YES

No

NA
Date \& Tine:

TC:

Scorer (s): 
TEST CONDITIONS: A hardstand area approximately 20 meters long is requ1red marked on both sides with pylons/engineer tape. The lane starts at 205" and narrows to $157^{\prime \prime}$ at the exit end. A start area not al1gned with the lane is required.

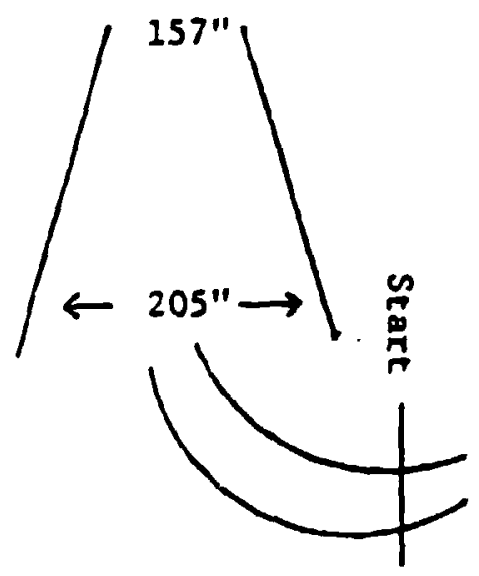

EQUIPMENT/PERSONNEL REQUIRED:

Equipment :

1 - M1 tank

$130^{\prime}$ engineer tape

$6-9=5^{\prime}$ stakes or pylons

2 - 2' stakes

1 - stopwatch

Felt market

$50^{\prime}$ measuring tape

\section{Personnel:}

1 TC

2 Scorars

\section{TEST PREPARATION:}

1. Erect the englneer tape on both sides of the lane no that $1 \mathrm{t}$ measures $205^{\prime \prime}$ wide at the wide end and narrowe co 157" wide at the exit and. Tape mugt be at or slightly below fender lavel.

2. Mark the engineer tape in quarters each approximately is' long.

3. Select a start polnt that 1o not allgned with the entrance to the course and mark with the short ytakes and englneer tape.

\section{TEST ADMINISTRATION (TC):}

1. Position the tank, engine off, at the start point.

2. Read the Ingtructions to the driver before mounting the tank.

3. When the driver has started the cank, conrand DKIVER, MOVE OUT and signal the scorer. 

INSTRUCTIONS TO THE DRIVER: During this test you must navigate the passage
without striking the stakes or engineer tape. I will not assist you in lining up the tank. You will drive with the hatch open. Do you have any questions?

$\because$

$\because$ 
Examinee Name:

Trial Number:

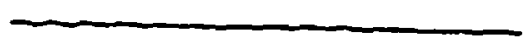

Date \& Time:

TC :

Scorer:

MEASURES :

RIGHT SIDE

Number of barrier strikes:

For each strike, describe:

1. Brief Sustained

2. Brief Sustained

3. Brief Sustained

4. Brief Sustained

5. Brief Sustained

Time :

$\begin{array}{lll}\text { Front } & \text { Rear } & \text { Entire Side } \\ \text { Front } & \text { Rear } & \text { Entire Side } \\ \text { Front } & \text { Rear } & \text { Entire Side } \\ \text { Front } & \text { Rear } & \text { Entire Side } \\ \text { Front } & \text { Rear } & \text { Entire Side }\end{array}$

Location: 1234 Location: 1234 Location: 1234 Location: 1234 Location: 1234

COIMENTS: 
Examlnee Name:

Date \& Time:

Trial Number:

TC :

Scorer:

MEASURES :

LEFT SIDE

Number of barrier strikes:

For each strike, describe:

2. Brief Sustained

3. Brief Sustained

4. Brief Sustained

5. Brief Sustained

Front Rear

Entire Side

Location: 1234

Front Rear Entire Side

Location: 1234

Front Rear

Entire Side

Front Rear

Entire side

Frone Rear

Entire Side

Location: 1234

Location: 1234

Location: 1234

Time:

CONMENTS : 
TEST CONDITIONS: A hardstand area with a series of six overhead gates and room to bypass each set of gates, 1.e.,

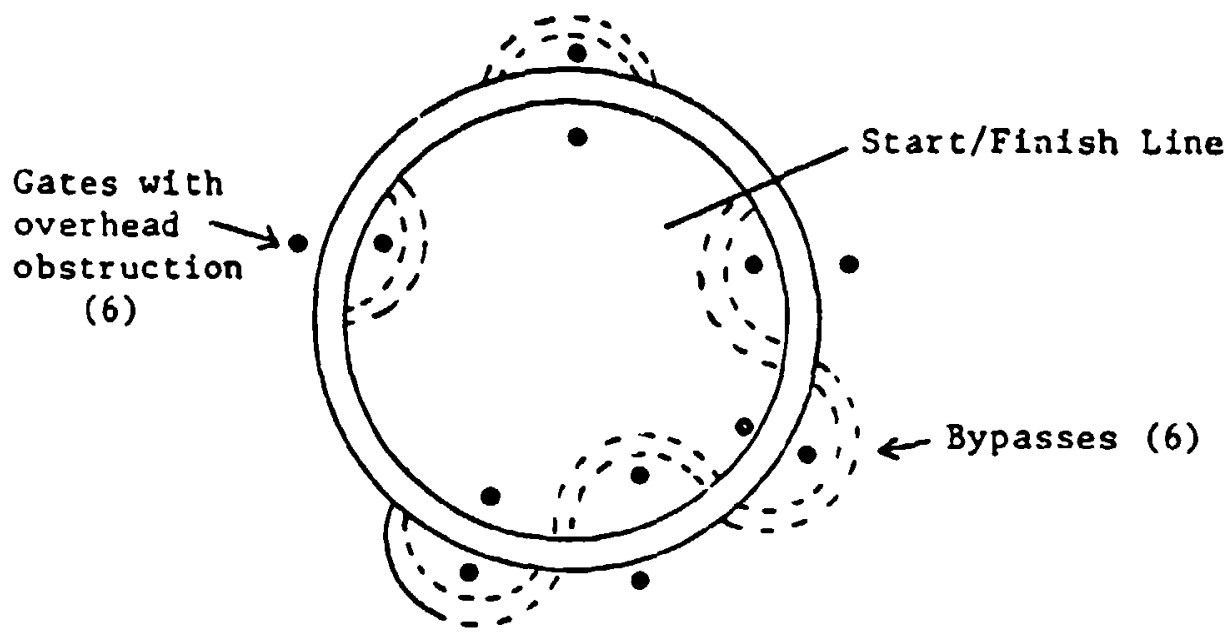

EQUIPMENT/PERSONNEL REQUIRED:

Equipment :

$$
\begin{aligned}
& 1 \text { - M1 tank } \\
& 2-24^{\prime \prime} \text { stakes } \\
& 10^{\circ} \text { engineer tape } \\
& 6 \text { - gates each consisting of } \\
& \quad 2 \text { - } 2 \times 4 \text { uprights } 12^{\prime}-14^{\prime} \text { long } \\
& \quad \text { and connecting onaterial } \\
& \quad \text { that 1s adjustable in height } \\
& 1 \text { - Stopwatch } \\
& 1-50^{\circ} \text { neasuring tape } \\
& 6-2 " \times 22^{\prime} \text { cards numbered } 1 \text { through } 6
\end{aligned}
$$

\section{TEST PREPARATION:}

1. Erect the six gates at points equidistant around the course.

a. Set the gates at a width of $170^{\prime \prime}$.

b. Set the overhead obstructions at the following heights in random order.

$$
\begin{aligned}
& \text { (1) } 119^{\prime \prime} \\
& \text { (2) } 118^{\prime \prime} \\
& \text { (3) } 117^{\prime \prime} \\
& \text { (4) } 116^{\prime \prime} \\
& \text { (5) } 115^{\prime \prime} \\
& \text { (6) } 114^{\prime \prime} \\
& \text { c. Affix a number card to each set of gales. }
\end{aligned}
$$


2. Mark the Start/Finish Line with stakes/engineer tape.

3. Drive through the course and through each bypass at least once so that bypass lanes are marked.

4. Change the location of the helght of the gates between each examinee and unobserved by the examinee. Change the height of at least two gates; one of which must always be the 114 " gate. The measurement for the height of each gate must be exact and must be of the six heights spectfled above.

\section{IEST ADMINISTRATION (TC):}

1. Position the tank, engine off, at the Start/Finish Line with gun tube to the rear.

2. Rerove the antenna(s).

3. Read the instructions to the examinee before mounting the tank.

4. Adjust the IC hatch to the protected open position. (NOTE: The TC may choose to ride in the loader's position for better vision and control.)

5. When the driver has started the engine, comnand DRIVER, MOVE OUT and signal the scorer.

6. Do not assist the driver in making the decision about passing or bypassing the gate. You may stop ard correct the driver if you see that he is going to strike one of the uprights. If this happens you must inform the scorer.

7. If the driver puils up to a gate and then decides to bypass, you may assist him in backing up. However, the decision to bypass must be made by the driver alone.

\section{TEST ADMINISTRATION AND SCORING (GROUND OBSERVER):}

1. Write down the height for each one of the gates on the scoresheet.

2. Start timing when the TC signals and stop then the rear of the tank crosses the Start/Finish Line.

3. Position yourself where you can observe each gate. Mark on the scoresheet whether the drive passed or bypassed each gate.

4. If any part of the tanik toushes any of the uprights or if the IC had to interfere with the driver to avoid striking an upright, note the gate and what occurred in the Coments section of the scoresheet.

5. After each examinee, change the location of the 114" overhead obstruction and at least one other otstruction height. However, all six heights must be consistently maintained. 
$\ddot{\varphi}$

Examinee Name:

Trial Number:

HeIght:

GATE 1

Bypass:

GATE 2

Bypass:

GATE 3

Bypass:

GATE 4

Bypass:

GATE 5

Bypass :

GATE 6

Bypass:

YES

MEASURES :

YES NO

Helght :

YES NO

Height:

YES NO

Height:

YES NO

Height:

YES NO

Helght:

NO
Date \& Time:

TC:

Scorer:

COMMENTS : 
TEST CONDITIONS: Terrain allowing tank speed of 15-20 mph and an area at least 250 meters long is required for the test. At least part of the cerrain (during the engagement portion) must be off road. An obstacle (ditch or ocher obstruction) which can be bypassed is located in the vehicle path. A target should be placed to facilltate laying the gun and evaluating the driving. The target should be located appruximately $30^{\circ}$ off the initial direction of travel, approximately 500 meters from the vehicle path in a location that can be viewed continuously from the gunner's position.

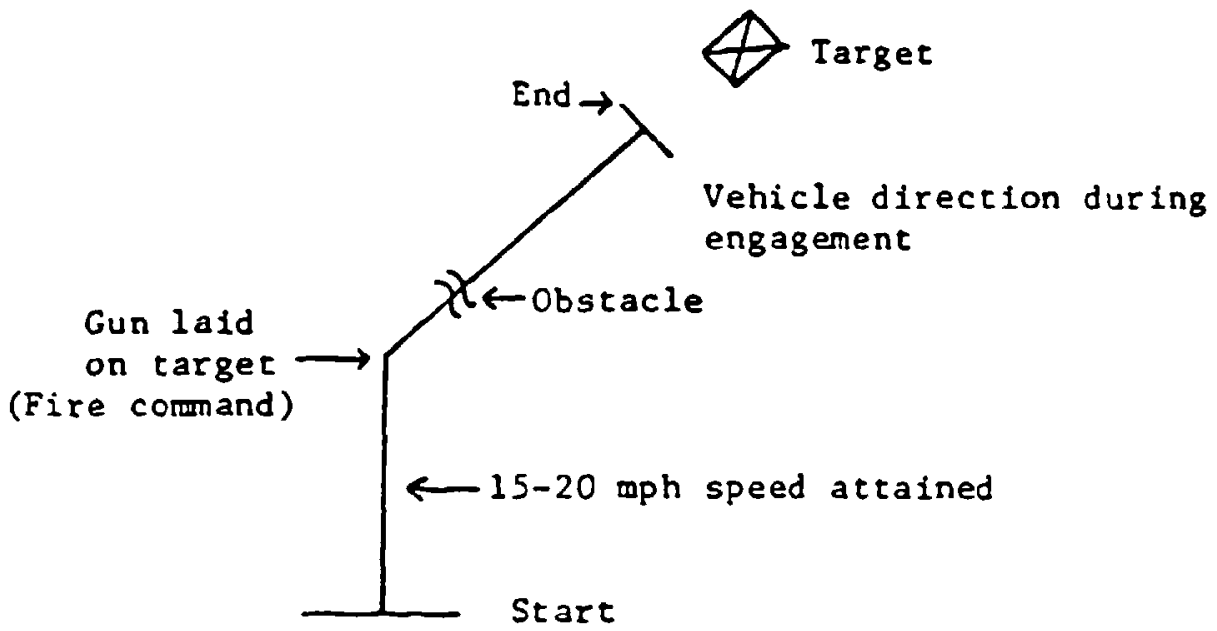

EQUIPMENT/PERSONNEL REQUIRED:

Equipment:

1 - M1 tank

Target, $24 " \times 24^{\prime \prime}$

1 - stopwatch

6 - 2' siakes

$20^{\prime}$ engineer tape

$2-2^{\prime \prime} \times 2^{\prime \prime} \times 8^{\prime}$ stakes
Personnel:

1 TC

1 Gunner

\section{TEST PREPARATION:}

1. Set up the $24^{\prime \prime} \times 24^{\prime \prime}$ panel at a distance of approximately 500 meters. Insure that the panel can be observed from the fire comand issue point on.

2. Mark the start point, the end point and the point where the fire comand will be issued.

3. If an obstacle does not raturally exist, construct one out oi logs, ditt or a ditch that will require that the driver to alter course. 
1. Position the tank, engine off, at the start point. Center the gun tube over the front slope.

2. Read the instructions to the driver before mounting the tank.

3. Insure the driver has his hatch locked before starting the test.

4. When the driver reaches the point for issuing the comrand, issue a fire command. Start timing on the alert element GUNNER.

5. When the driver reaches the stop point announce CEASE FIRE and stop timing.

6. If the driver does not reach an estimated 15 oph before the location for issuing the fire command, tell him to speed up.

7. Count the number of times that the transmission shifted up or down between the aler: element of the fire command and CEASE FIRE and enter it on the scoresheet. Do this without consulting with the gunner.

\section{TEST ADMINISTRATION AND SCORING (GUNNER):}

1. Announce IDENTIFIED as soon as the TC lays you on the target.

2. Attempt to maintain the cross hairs on the $24^{\prime \prime} \times 24^{\prime \prime}$ panel from IDENTIFIED unt11 CEASE FIRE. Estimate the percent of time you were able to keep the crosshairs on the target and mark it on the scoresheet.

3. Count the number of times that the transmission shifted up or down between the alert element of the fire command and CEASE FIRE and enter it on the scoresheet. Do this without consulting with the TC. 
CONTROL TANK DURING MAIN GUN ENGAG EMENT

TC EVALUATION

Examinee Name:

Date \& Time:

Trial Number:

TC:

Scorer :

INSTRUCTIONS TO DRIVER: During this test you will drive the vehicle during a moving main gun engagement. You must have your hatch closed. You must keep the front of the tank oriented on the enemy location. The required speed is $15-20 \mathrm{mph}$. Do you have any questions?

MEASURES :

1. Oriented the front of the tank towards the enemy.

YES NO

2. Avoided obstacle.

YES NO

3. Announced turn to avold obstacle.

YES NO

4. Reorlented tank toward target after passing obstacle. IES NO

5. Number of times that transmission shifted after fire command:

6. Time from alert element to CEASE FIRE:

COMMENTS : 
TEST CONDITIONS: Terrain allowing tank speed of 15-20 mph and an area approximately 200 meters long and 50 meters wide is required. At least one adequate hide position is required which must be visible during the approach portion of the driving.

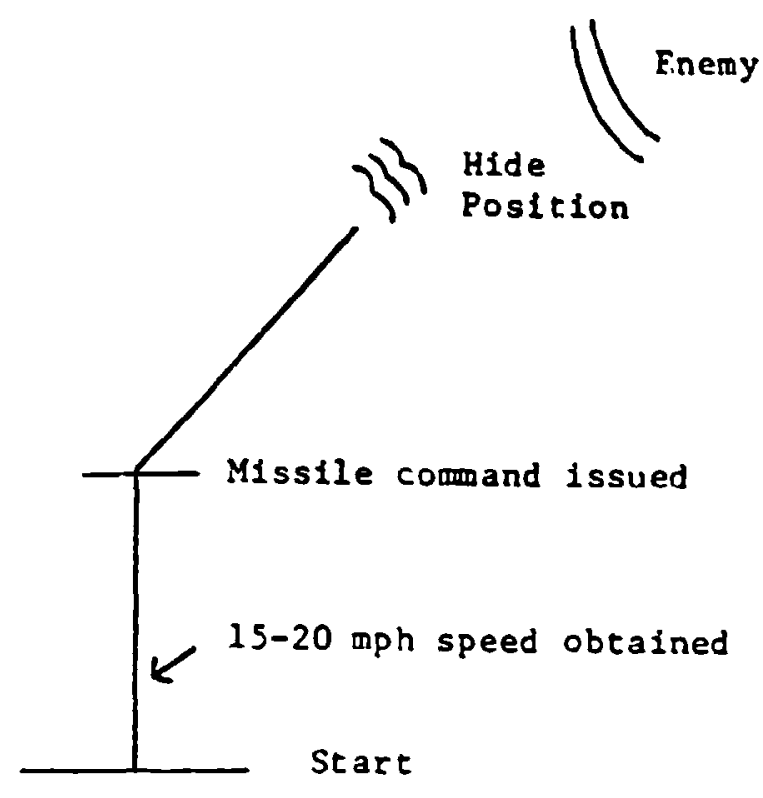

EQUIPMENT/PERSONNEL REQUIRED:

Equipment:

$$
\begin{aligned}
& 1 \text { - Ml tank } \\
& \text { Tape, adhesive, } I^{\prime}, \text { yellow } \\
& \text { 1 - binoculars } \\
& 4 \text { - 2' scakes } \\
& 1 \text { - stopwatch } \\
& 20^{\prime} \text { engineer tape }
\end{aligned}
$$

\section{Personnel:}

1 TC

1 Scorer

\section{TEST PRFPARATION:}

1. Select an enemy location that is visible from the start point and from the hide position. The enemy location should be a minimum of 500 meters frow the hide position.

2. Mark the start point with a stakes and engineer tape.

3. Identify a location for lssuing the comand. This location should be $f$ ar enough from the start point to allow the driver to reach 15-20 mph and about 10-12 seconds from the nearest acceptable position, and visible from the enemy location. If the location is not marked naturally (such as by a tree), nark the location with stakes ano engineer tape.

4. Place two-foot long segments of adhesive tape horizontally at interrals on the turret in three rows: at the bottom, in the siddle, and at the top of the turret. Do the same on the hull. 
TEST ADMINISTRATION AND SCORING (TC):

1. Position the tank, engine of $f$, at the start point.

2. Read the instructions to the driver before mounting the tank.

3. Insure tha driver has the hatch closed before starting the test.

4. When the driver reaches the location for issuing the courand, announce MISSILE, DUCK. Begin timing.

5. If the driver does not reach an estimated $15 \mathrm{mph}$ before the location for the announcement, tell hil to speed up.

6. When the driver reaches his final position, stop timing and signal the observer.

7. Do not assist the driver in moving to or into the hide position.

\section{TEST ADMINISTRATION AND SCORING (OBSERVER):}

1. Select and mark a position at the enemy location. Use this position each time the rest is run. If at 500 meters or less, always observe in the same body position, i.e., standing, kneeling or sitting.

2. Observe the tank through the binoculars. When the TC signals that the driver is in the final position, count the number of tape segments visible on the turret and on the hull.

3. Usiag the tank pictures on the scoresheet, outline the portion of the tank that is visible.

4. Rate the amount of exposure after the initial stop and after the TC's signal that the driver is in the final position. 

REACT TO TC COMMAND - MISSILE, DUCR

OBSERVER EVALUATION

Examinee Name:

Trial Number:
Date \& Time:

TC:

Scorer :

\section{IEASURES:}

1. Which describes tank after initial stop? (Circle one)

Maintained Concealment Intermittenc Exposure Exposed Throughout

2. Number of tape segments visible:

On turret:

On hull:

3. Outline portion of tank exposed:
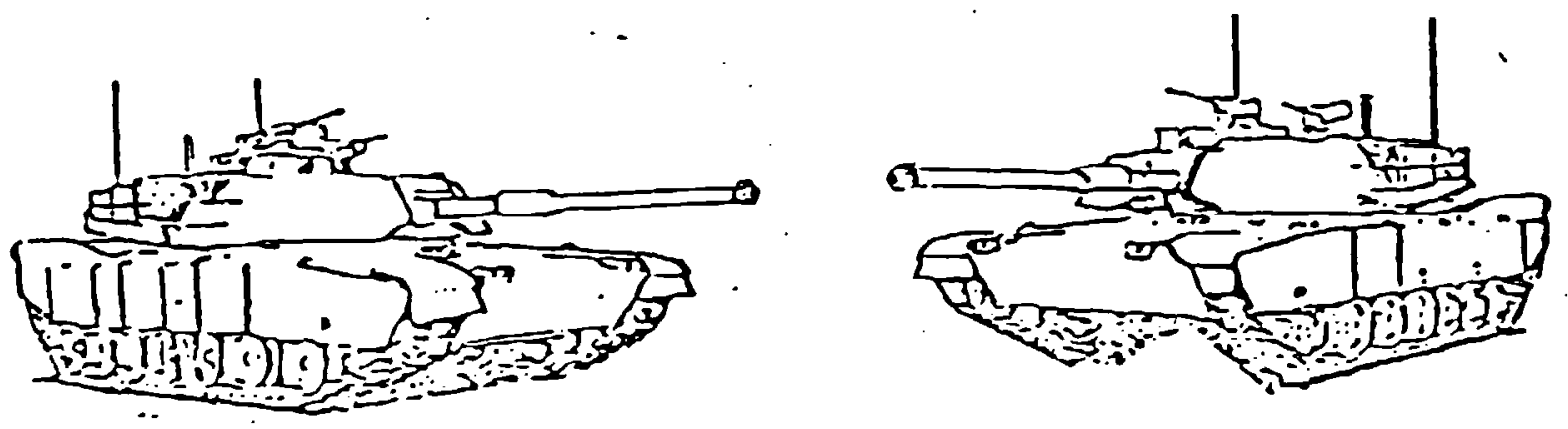

CO:MENTS: 
TEST CONDITIONS: Terrain allowing tank speed of 15-20 mph and an area approximately 200 meters $10 n g$ and 50 meters wide is required. At least one adequate hull defilade position must be visible during the approach portion of the driving.
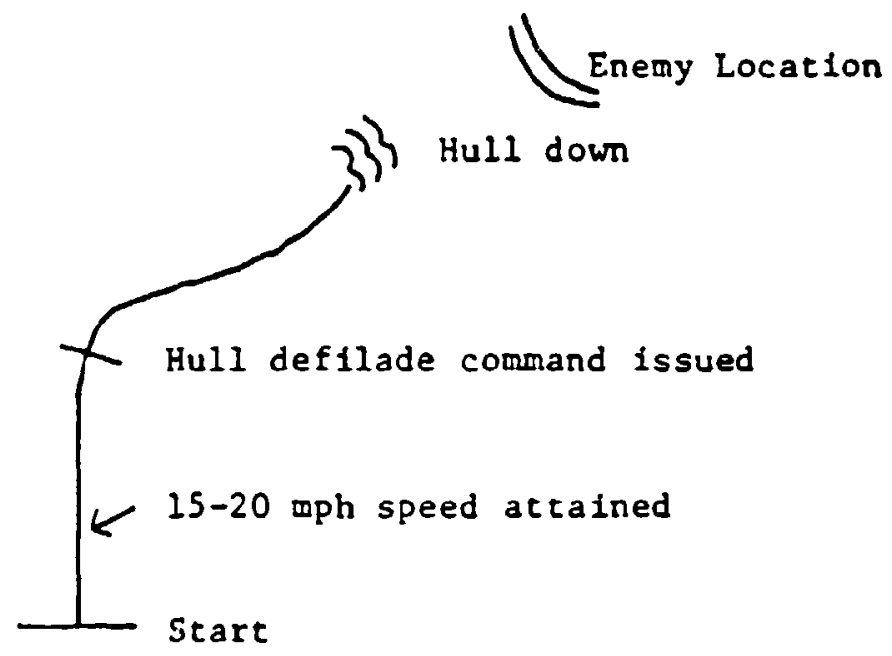

EQUIPMENT/PERSONNEL REQUIRED:

Equipment:

1 - Ml tank

Tape, adhesive, $1 "$, yellow

1 - binoculars

2 - 2' stakes

$20^{\prime}$ engineer tape

1 - stopwatch
Personnel:

1 TC

1 Scorer

\section{TEST PREPARATION :}

1. Select an enemy location that is visible from the start point and from the hull defilade position. The enemy location should be a minimum of 500 meters from the defilade position.

2. Yark the start point with the stakes and engtneer tape.

3. Identify a location for issuing the command. This location should be far enough from the start point to allow the driver to reach 15-20 mph and about 10-12 seconds from the nearest acceptable hull defilade position, and visible from the enemy location. If the location is not marked naturally (such as by a tree), mark the location with stakes and engineer tape.

4. Place two-foot lung segments of tape horizontally at intervals along the edge of the front slope and along the middle of the skires. Tape a second and third row of segments equidistant from the middle row. Repeat the same process for the turret. 
TEST ADMINISTRATION AND SCORING (TC):

1. Position the tank, engine off, at the start point.

2. Read the instructions to the driver before mounting the tank.

3. Insure the driver has the hatch closed before starting the test.

4. When the driver reaches the location for 1ssuing the comand, announce DRIVER, HULL DEFILADE. Begin timing.

5. If the driver does not reach an estimated $15 \mathrm{mph}$ before the location for the announcement, tell $\mathrm{h}$ im to speed up.

6. The driver may adjust his position once he arrives at the hull defilade location. Keep track of the number and type of adjustments.

7. When the driver reaches his final position, stop timing and signal the observer.

8. After the driver reaches his final position, look through the GPS extension and adjust. the gun if necessary. If you can see the enemy location score Measure 1 YES.

9. Do not assist the driver in moving to or into the defilade position.

TEST ADMINISTRATION AND SCORING (OBSERVER):

1. Select and mark a position at the enemy location. Use this position each time the test is run. If at 500 meters or less, always observe in the same body position, 1.e., standing, kneeling or sitting.

2. Observe the tank through the binoculars. When the TC signals that the driver is in the final position, count the number of tape segments visible on the hull and on the turret. Record the number of segments separately for the front and the side.

3. Using the tank piccures on the scoresheet, outline the portion of the tank that 1s visible. 
REACT TO TC COMMAND - HULL DEFILADE

TC EVALUATION

(1)

Examinee Name:

Trial Number:

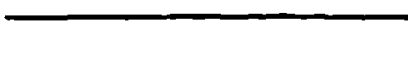

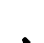

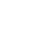

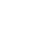

Date \& Time:

TC:

Scorer:

INSTRUCTIONS TO DRIVER: During this test you must react to a command given by the TC. The (Indicate location) is a suspected enemy location. You mist operate with the hatch closed and at an initial speed of 15-20 mph. Once I 1ssue you the command I will not assist you in following the command. Do you have any questions?

MEASURES :

1. Was mask clearance obtained? YES NO

2. Speed entering position (Circle one):

$$
\text { Appropriace Too Slow }
$$

3. Stopping (Circle one):

$$
\text { Smooth Jerky Abrupt }
$$

4. Number of adjustments after first stopping:

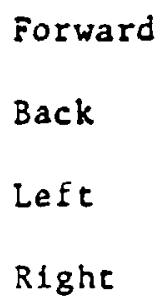

5. Time from command to final position: 
REACT TO TC COAMAND - HULL DEFILADE

ENEM OBSERVER EVALUATION

Examinee Name:

Trial:

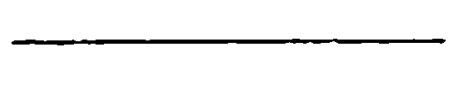

Date \& Tine:

TC:

Scorer (s):

MEASURES :

1. Tape segments visible on hull:

Location Number

Front

side

2. Number of tape segments visible on turret:

3. Outline portion of tank exposed:
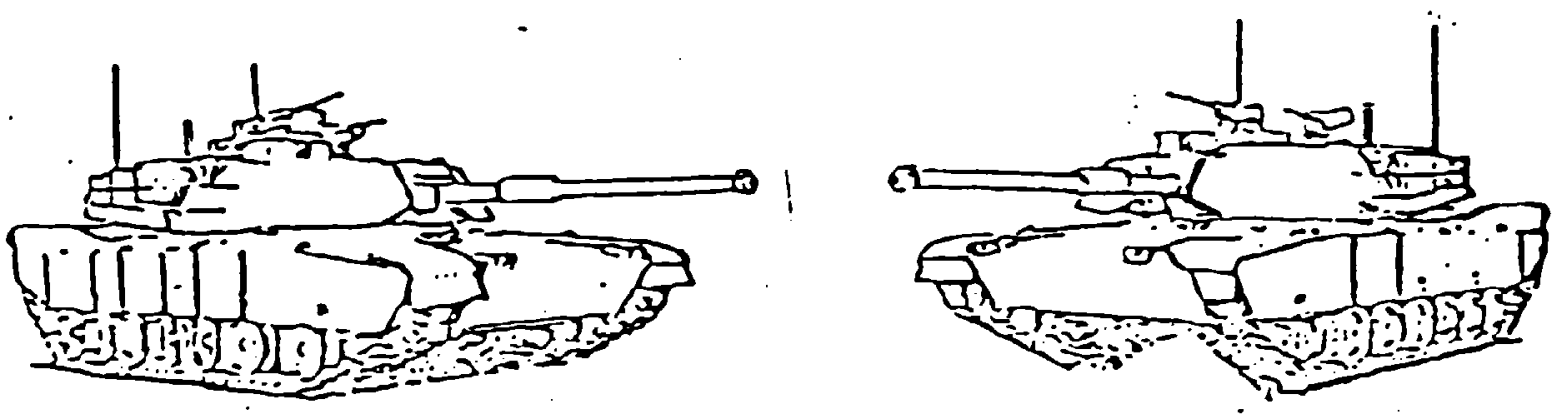

COPRENTS: 
TEST CONDITIONS: Test conducted in terrain allowing a hull defilade position. Terrain should be uneven and uphill or inclined if possible. Concealment should be present and terrain may be wooded. A track, approximately 90 meters long, is identified on the ground. This should not be a straight line. A stop point must be identifiable on the ground by the driver. Right and left limits should also be defined at the stop point approxiinately 160" wide, i.e.,

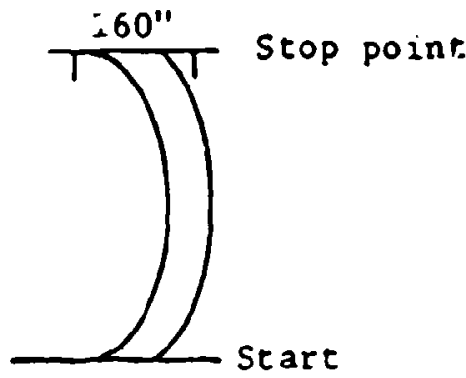

EQUIPMENT/PERSONNEL REQUIRED:

Equipment :

1 - MI tank

$30^{\prime}$ engineer tape

8 - 2' stakes

1 - stopwatch

Measuring tape
Personnel:

1 TC

1 Scorer

\section{TEST PREPARATION:}

1. Mark the stop point on the ground with engineer tape marking the forward point and right and left limtes 160" wide. Secure the engineer tape for the right and lift limits flush to the ground.

2. Mark the start point on the ground.

\section{IEST ADMINI STRATION AND SCORING (TC):}

1. Position the tank, englne of $f$, at the start point with the gun tube centered over the front slope.

2. Read the instructions to the driver. If the stop point cannot be seen from the start point, walk the driver to a point where he can observe it.

3. Insure the driver has his hatch locked, transmission in park and engine at tactical idle before issuing the comand. 



\section{SCORESHEET}

\section{ACCELERATION AND STOPPING}

TC EVALUATION

Examinee Name:

Trial Number:
Date \& Time:

TC:

Scorer:

INSTRUCTIONS TO DRIVER: During this test you must move from your present location to a firing position marked by the - You must move as rapidly as possible but you will also be scored on the smoothness of your move. In other words, you must not cause the gunner to lose or delay his sight picture. You must stop as close as possible to the - Once the tank stops you will not be allowed to adjust the position. When you moint the tank you mist close the hatch, start the engine, and place the tactical idle switch on. Leave the transmission in $P$ and the parking brake on until I tell you to move. Move out when I give the command, however, I will not give you a cormand to stop; you must stop on your own. Any questions?

\section{MEASURES :}

1. Accleeration/Deceleration (Circle one):

$$
\text { Smooth Jerky (Acceptable) Jerky (Unacceptable) }
$$

2. Stop (Circle one):

$$
\text { Swooth Jerky Too Slow Abrupt }
$$

3. Time from comand to stopping:

\section{COMENTS :}


Examinee Name:

Trial Number:

MEASURES :

1. Distance from Stop line:

Over

Short

2. Was tank within boundaries?
Date $\&$ Tine:

Scorer :

If No:

Distance outside right boundary:

Distance outside left boundary:

COMMENTS : 

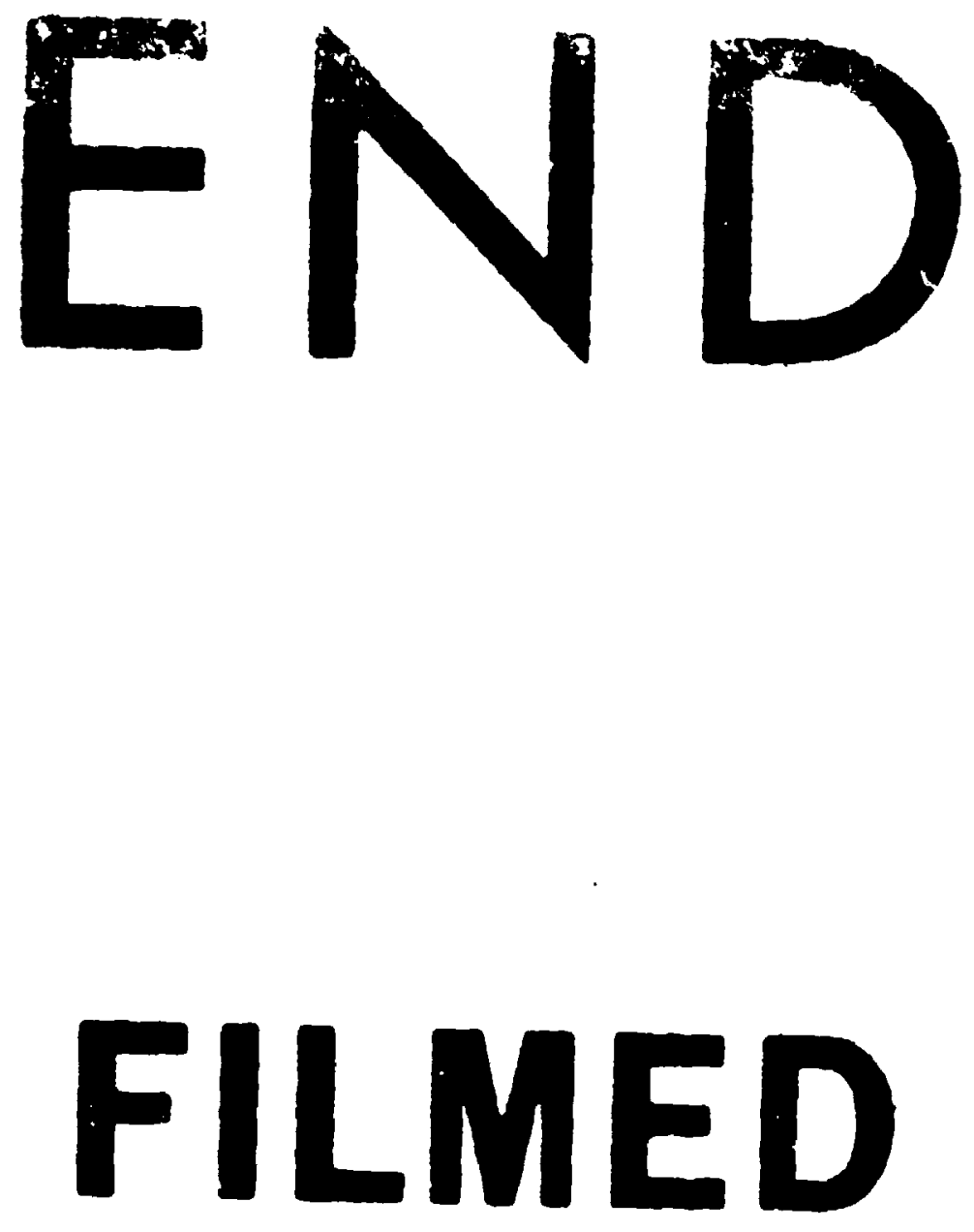

$$
\text { 8-85 }
$$

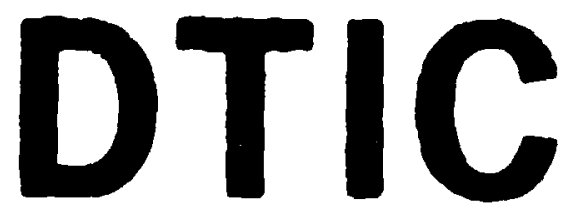

